\title{
Analyst
}

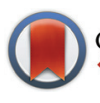

CrossMark

Cite this: Analyst, 2015, 140, 2573

Received 7th November 2014 Accepted 13th December 2014

DOI: 10.1039/c4an02049a

www.rsc.org/analyst

\section{SIFT-MS and FA-MS methods for ambient gas phase analysis: developments and applications in the UK}

\author{
David Smith ${ }^{\star a}$ and Patrik Španěl ${ }^{a, b}$
}

Selected ion flow tube mass spectrometry, SIFT-MS, a relatively new gas/vapour phase analytical method, is derived from the much earlier selected ion flow tube, SIFT, used for the study of gas phase ion-molecule reactions. Both the SIFT and SIFT-MS techniques were conceived and developed in the UK, the former at Birmingham University, the latter at Keele University along with the complementary flowing afterglow mass spectrometry, FA-MS, technique. The focus of this short review is largely to describe the origins, developments and, most importantly, the unique features of SIFT-MS as an analytical tool for ambient analysis and to indicate its growing use to analyse humid air, especially exhaled breath, its unique place as a on-line, real time analytical method and its growing use and applications as a non-invasive diagnostic in clinical diagnosis and therapeutic monitoring, principally within several UK universities and hospitals, and briefly in the wider world. A few case studies are outlined that show the potential of SIFT-MS and FA-MS in the detection and quantification of metabolites in exhaled breath as a step towards recognising pathophysiology indicative of disease and the presence of bacterial and fungal infection of the airways and lungs. Particular cases include the detection of Pseudomonas aeruginosa infection of the airways of patients with cystic fibrosis (SIFT-MS) and the measurement of total body water in patients with chronic kidney disease (FA-MS). The growing exploitation of SIFT-MS in other areas of research and commerce are briefly listed to show the wide utility of this unique UK-developed analytical method, and future prospects and developments are alluded to.

\section{Introduction}

Mass spectrometric analysis in its various forms has been exploited for decades in biomedical research and is becoming increasingly important in biochemical analyses and clinical screening. Widely used techniques include gas chromatography mass spectrometry, GC-MS, which often uses preconcentration methods, and high performance liquid chromatography mass spectrometry, HPLC-MS. More recently, electrospray ionisation, ESI, coupled with tandem MS and matrix assisted laser desorption ionisation, MALDI, usually combined with high resolution time-of-flight, TOF-MS, is increasingly being exploited. These powerful analytical methods are mostly not useful for "ambient analysis", i.e. direct real time analysis of samples placed in air at atmospheric pressure, because they usually involve sample preparation or extraction that delay ana-

\footnotetext{
${ }^{a}$ Institute for Science and Technology in Medicine - Keele University, Guy Hilton Research Centre, Thornburrow Drive, Hartshill, Stoke-on-Trent, ST4 7QB, UK. E-mail: d.smith@keele.ac.uk

${ }^{b}$ J. Heyrovsky Institute of Physical Chemistry, Academy of Sciences of the Czech Republic, Dolejškova 3, Praha 8, Prague, Czech Republic
}

lysis. Most importantly, these techniques are not accurately quantitative without using external or internal standards. Nevertheless, they have become essential in clinical medicine when instantaneous targeted analysis is not a priority such as for liquid phase analyses of blood, serum and urine and solid phase analyses of biological samples (such as bacteria) deposited or placed on solid matrices.

Due to the early pioneering work of Linus Pauling using GC-MS and subsequent work by many others, it is now known that there is a large number of volatile organic compounds, VOCs, in exhaled breath. ${ }^{1}$ Since Pauling's suggestion that these VOCs may open a non-invasive window to human physiology and pathophysiology and, in principle, could be exploited for clinical diagnosis, the science of breath analysis has increasingly attracted the attention of analytical chemists and clinicians. At this time of writing, there are many research groups worldwide researching this topic, which prompted the production of two research texts devoted to the topic of analysis of trace VOCs in exhaled breath and in the vapour headspace of biological fluids such as urine and mammalian and bacterial cell cultures. ${ }^{2,3}$ Scrutiny of the published literature reveals that the most widely used analytical method for breath 
analysis has been and remains GC-MS, but as stated above it cannot be used for direct real time, accurately quantitative ambient analysis of air, fluid headspace or exhaled breath.

Clearly, it is desirable to devise instrumentation by which the trace metabolites present in single exhalations of breath can be quantitatively analysed in real time at precision and accuracy to be useful for clinical diagnosis. This was the goal that the authors of this paper set themselves at Keele University UK in the year 1996, almost 20 years ago. Thus, focused research and development over several years has realised the analytical techniques called selected ion flow tube mass spectrometry, SIFT-MS, and flowing afterglow mass spectrometry, FA-MS. Initial developments of these techniques were carried out using very large, laboratory-based SIFT-MS instruments. These have evolved to much smaller and readily transportable instruments ${ }^{4}$ that are being exploited for real time ambient analysis of exhaled breath and in other areas of research where trace gas analysis is of value, such as environmental air analysis and food science, and in important practical applications exemplified by container air monitoring to detect illicit materials and to protect the health and safety of customs officials. $^{5}$ SIFT-MS has been adopted in several research laboratories worldwide, not least in the UK. In the spirit of a themed collection of Analyst on analytical science in the UK, this paper reviews the scientific and instrumental developments of SIFT-MS and FA-MS and its exploitation for various research programmes in UK universities and research establishments (UK locations indicated in Fig. 1). The focus is largely on their application to breath analysis and related topics in physiology and medicine, but also mentioning other areas of research in which these novel analytical techniques are being exploited.

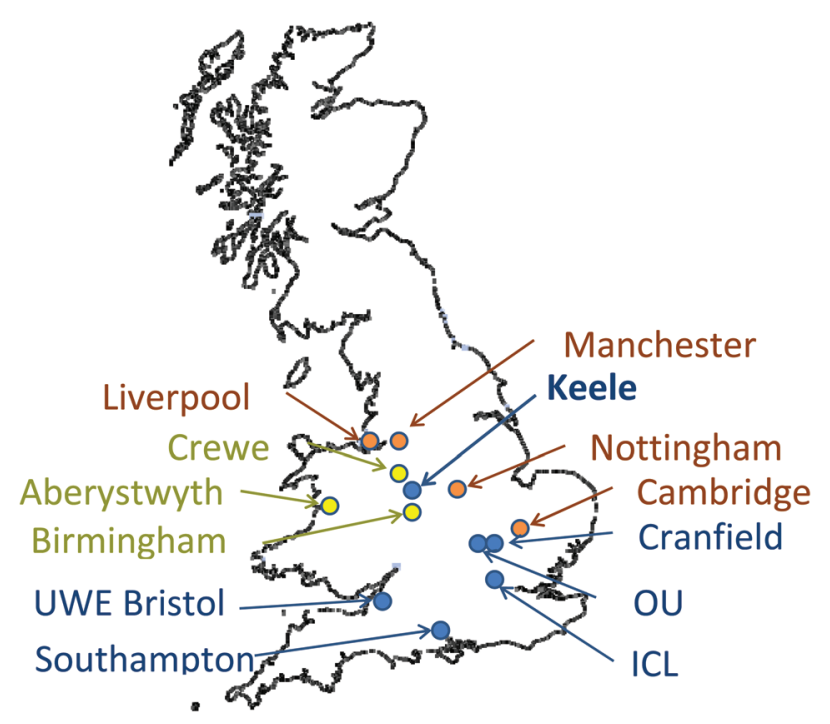

Fig. 1 Geographical locations of UK universities, hospitals and research establishments that relate to the origins of SIFT, SIFT-MS and FA-MS (yellow), their further developments and applications (blue) and the current interdisciplinary collaborations (brown).

\section{Breath analysis and the analytical instrumentation required}

As background to the instrumentation required to achieve realtime quantitative breath analysis, it is instructive to state the major objectives of breath research and analysis:

- Identify, quantify and recognize abnormal concentrations of common volatile metabolites in the very humid air that is exhaled breath.

- Differentiate between endogenous and exogenous volatile breath compounds.

- Track changes in breath metabolite concentrations accurately over short and long periods in support of longitudinal studies, pharmacokinetics, and the efficacy of therapy.

- Identify new volatile biomarker compounds in breath related to specific diseases and infections.

These requirements are common also to the many nonvolatile biomarkers present in other biological fluids that are widely used in medical diagnosis. So what is a biomarker? A widely accepted definition, used by the National Institute of Health (NIH) is: ${ }^{6}$ 'a characteristic that is objectively measured and evaluated as an indicator of normal biological processes, pathogenic processes, or pharmacologic responses to an intervention.' Example: the blood cholesterol level. The committee defines 'objectively' to mean 'reliably and accurately'. Thus, the discovery of biomarkers in the form of reliable and accurately measured concentrations of volatile compounds must ultimately be a major objective of breath analysis research. Therefore, in order to fulfil the requirement for objective measurement, the most important, and indeed the most challenging aspect of breath research is the development of analytical methods that can realise positive identification and accurate quantification of endogenous trace compounds at appropriately low levels to be useful clinically as biomarkers.

The demands on the desirable instrumentation are increased when the objective is real time analysis of single breath exhalations for which only a few seconds are available for sample collection and analysis. This time constraint can seriously diminish the analytical sensitivity, which can be crucial when it is realised that many of the trace gas metabolites and biomarkers are present in the very humid exhaled breath at concentrations (partial pressures) of just a few partsper-billion by volume, ppbv, or lower. It is also essential to minimise losses of trace metabolites (and water vapour; see later) from the breath sample due to surface adsorption on sample entry lines to the analytical reactor. However, if these stringent conditions can be met, breath analysis can be carried out non-invasively and quickly, obviating both sample collection and delayed off-line analysis that can compromise the sample. As we will show in this review, these demanding requirements have been met by SIFT-MS and so ambient analysis of environmental air, exhaled breath and other humid air samples can be accurately achieved in real time. 
It is clear that simply to identify unusual patterns of metabolites in exhaled breath via the comparison and statistical interpretation of multiple ion mass spectra or ion mobility patterns obtained from the analysis of breath samples from healthy and diseased persons circumventing positive identification or adequate quantification of the trace compounds involved, falls short of fulfilling the aforementioned criterion for biomarkers. Although such data mining measures are useful in the search for overall differences in breath composition, and they can offer a basis for refocused research on true biomarker identification, ultimately they are unlikely to find use in clinical applications. Importantly, it must also be forcibly stated that even when true biomarkers have apparently been identified, their clinical value in diagnosis and their benefit to the patients must be independently and objectively tested and verified, preferably by multicentre studies. Even though we have chosen to emphasise the interesting application of ambient analysis to exhaled breath analysis, there are wider applications where instant air analysis is becoming increasingly valuable such as in environmental monitoring, food science and health and safety practice. Brief references will also be given to these applications in this short review.

\section{Principles of the SIFT technique and the SIFT-MS analytical method}

To reiterate, a major object at the onset of this analytical research was to realise a technique that could accurately and simultaneously analyse in real time several of the trace volatile compounds that are present in single exhalations of breath, obviating sample collection prior to analysis, thus immediately providing supporting diagnostic data to the attending physician in the clinical setting. As we will show, this has been achieved with the latest SIFT-MS and FA-MS instruments.

In principle, direct analysis of air/breath can be achieved by simply introducing a sample into a commonly used electron ionisation, EI, ion source of a conventional mass spectrometer, thus collectively ionising the trace constituents of the sample along with the major air compounds $\left(\mathrm{N}_{2}, \mathrm{O}_{2}, \mathrm{Ar}, \mathrm{H}_{2} \mathrm{O}, \mathrm{CO}_{2}\right)$, immediately followed by analysis of the ion mixture by some form of MS. However, the resulting mass spectra obtained by this procedure are extremely complicated, comprising few large product ion peaks originating from the major neutral components and many minor peaks originating from the trace compounds. Furthermore, there are multiple overlaps of these product ions at several $\mathrm{m} / \mathrm{z}$ (mass-to-charge ratio) values that render identification and quantification of the original trace compounds extremely difficult, if not impossible. Not surprisingly, this procedure has not been successfully used in breath research.

To alleviate some of these intractable problems there have been considerable innovations in analytical techniques, especially in the use of compound separation in GC columns prior to MS analysis, ${ }^{7,8}$ but the appreciable sample collection and preparation times negate the real time requirement for ambient analysis. So a major focus has been on "soft ionisation" or "chemical ionisation", CI, of analyte compounds prior to MS analysis. This involves the selective ionisation of the trace compounds in the sample using judiciously chosen reagent cations (sometimes anions, but rarely) that do not react at significant rates with the major air compounds $\left(\mathrm{N}_{2}, \mathrm{O}_{2}, \mathrm{H}_{2} \mathrm{O}, \mathrm{Ar}, \mathrm{CO}_{2}\right)$. Thus, CI circumvents the energetic electron collisions that result in molecular fragmentation and generates just one (or few) characteristic product ion(s) for each neutral analyte, minimises product ion coincidences and allows complex air mixtures to be analysed with considerably less ambiguity. This is the ionisation method chosen by the authors in the development of both SIFT-MS and FA-MS, following the expertise they acquired over many years in the development and detailed application of the selected ion flow tube, SIFT,, 10 and the flowing afterglow Langmuir probe, FALP, ${ }^{11,12}$ techniques to the study of gas phase ionic and electronic reactions. ${ }^{13}$

\section{The SIFT technique}

The SIFT technique, which is the basis of SIFT-MS, was conceived and developed nearly 40 years ago in Birmingham University UK by N.G. Adams and D. Smith. ${ }^{10,14}$ It quickly became a standard method for the study of ion-neutral reactions at thermal interaction energies with its adoption in several laboratories worldwide. ${ }^{15}$ Initially, it was developed to satisfy the need for the great deal of kinetic data on gas phase ion-neutral reactions that are required to describe the production of the molecules observed in cold interstellar clouds. ${ }^{13}$ However, its use quickly extended to the studies of the ionic reactions relevant to other media, notably the ionised terrestrial atmosphere, ${ }^{16,17}$ studies of which have a direct bearing on the development of SIFT-MS, as will see later. Thousands of ionneutral reactions have been studied using the SIFT technique in several laboratories around the world, not least in the UK (see ref. 10, 13 and 18-20 and the references therein). This has resulted in a large kinetics database, a better understanding of the fundamental aspects of ion-neutral reactions, and an appreciation of the ion chemistries occurring in naturally ionised media. ${ }^{17}$ Some of these early kinetics data are adding to the kinetics library needed for SIFT-MS analyses, as will be mentioned later. ${ }^{21-23}$

The principle of the SIFT technique is as follows. Mixtures of positive ions, electrons and negative ions are created in a gas discharge ion source and from this plasma mixture a current of ions of a chosen mass-to-charge ratio, $\mathrm{m} / z$, is obtained using a quadrupole mass filter. ${ }^{10,24,25}$ These precursor ions (cations or anions) are injected into a fast-flowing inert carrier gas (usually pure helium at a pressure of typically $100 \mathrm{~Pa}$ (about 1 Torr)) through a Venturi-type inlet. ${ }^{10,14,21,26}$ Thus, a cold precursor ion/helium gas swarm is created possessing a Maxwellian speed distribution appropriate to the temperature of the helium carrier gas (usually $300 \mathrm{~K}$, but can range from $80 \mathrm{~K}$ to $600 \mathrm{~K}$ in more sophisticated instruments ${ }^{24,27}$ ). This swarm is convected along the flow tube and the ions are sampled downstream via a pinhole orifice and 
focused into a differentially pumped quadrupole MS. ${ }^{4,26}$ After $\mathrm{m} / \mathrm{z}$ analysis they are detected and counted by an electron multiplier/pulse counting system.

To determine the rate coefficient, $k$, and ion products of the chosen injected ions with the molecules of a reactant gas, a controlled and measured flow rate of the reactant gas is introduced into the helium carrier gas and the count rates of the precursor ions (reducing) and the product ions (increasing) are measured by a downstream MS/detection system. A simple analysis of the count rate of the precursor ions as a function of the reactant gas flow rate provides the $k$ for the reaction. There is more than one product ion generated in most ion-molecule reactions; analysis of the count rates of the product ions provides the percentage product ion distribution. Many ion-molecule reaction processes that occur in ionised media have been recognised and investigated by extensive SIFT studies involving many types of organic molecules, formerly at Birmingham University, latterly at both Keele University and the J. Heyrovsky Institute in Prague, and in other laboratories over the years. ${ }^{15,21}$ Much of the essential kinetics data needed for wideranging SIFT-MS analyses have been obtained by these studies, as will be shown later.

\section{The SIFT-MS analytical method}

The essence of the SIFT-MS analytical method is as follows. If the rate coefficient, $k$, is known for the reaction of a particular precursor ion (now the reagent ion) with reactant molecule, $\mathrm{M}$, (now the analyte molecule) then, in principle, the decrease in the reagent ion count rate, $I$, (as monitored by the downstream MS) as analyte molecules, M, flow into the carrier gas can be used to determine [M], the number density of $\mathrm{M}$ in the helium carrier gas of the SIFT-MS instrument. However, if a sample of gas (such as exhaled breath) containing many different trace gases is introduced simultaneously into the carrier gas, then the reduction in $I$ will reflect the net effect of the reactions of all the individual analyte gases, so discriminant analysis of the mixture will not be achieved by recording $I$ only. Furthermore, for trace gas analysis, the fractional reduction in $I$ is, by necessity, very small ${ }^{28}$ and therefore measurement accuracy would be poor. But if the reactions of each $\mathrm{M}$ with the reagent ions result in characteristic product ions at a known $\mathrm{m} / \mathrm{z}$, the measured signal levels of these characteristic ions, even though very small, will both identify and allow the individual trace compounds $\mathrm{M}$ in the mixture to be quantified to good accuracy and precision. ${ }^{4,21,29-31}$ This then is the principle of SIFT-MS analysis. The actual procedure to obtain the raw data on reagent/product ion count rates is briefly alluded to later.

A simple example of this analytical ion chemistry is the reaction between the most commonly used reagent ion $\mathrm{H}_{3} \mathrm{O}^{+}$ (see below) and analyte molecules, $\mathrm{M}$, which generally proceeds via proton transfer:

$$
\mathrm{H}_{3} \mathrm{O}^{+}+\mathrm{M} \rightarrow \mathrm{MH}^{+}+\mathrm{H}_{2} \mathrm{O}
$$

It is simple to show that the number density of the characteristic product ions $\left[\mathrm{MH}^{+}\right]_{t}$ is related to the number density of the reagent ions $\left[\mathrm{H}_{3} \mathrm{O}^{+}\right]$thus:

$$
\left[\mathrm{MH}^{+}\right]_{t}=\left[\mathrm{H}_{3} \mathrm{O}^{+}\right] k[\mathrm{M}] t D_{\mathrm{e}}
$$

$k$ is the rate coefficient for the reaction and $t$ is the reaction time. $D_{\mathrm{e}}$ is a differential diffusion enhancement coefficient that accounts for the fact that the reagent ions and the product ions diffuse through the helium carrier gas to the walls of the SIFT-MS flow tube at different rates. This phenomenon influences the relative number densities of the reagent and product ions arriving at the downstream ion sampling orifice (see Fig. 2) and, consequently, their count rates as determined by the downstream analytical MS/detection system. This phenomenon, and also mass discrimination against larger $\mathrm{m} / \mathrm{z}$ ions that usually occurs in the analytical quadrupole mass spectrometer, must be accounted for to obtain accurate quantitative analyses. ${ }^{26,32-34}$ It is interesting, and to some degree corrective, that differential diffusion enhances the count rates of the heavier ions and mass discrimination diminishes their count rates. Thorough studies $^{26,34}$ of these opposing effects have resulted in the formulation of a sophisticated algorithm by which absolute analyte concentrations in air are obtained. ${ }^{32}$ This algorithm contains as the primary measured parameter the ratio of the total product ion count rate to the total reagent ion count rate (including both hydrated reagent and product ions; see below). Note that if any drift/variation occurs in the reagent ion count rate due to discharge plasma source variations, these changes are reflected directly in the product ion count rates and so the analysis is not compromised. Thus, the accurate measurements of reagent and characteristic product ion count rates by the downstream mass spectrometer detection system provide real-time quantifications of trace gases in complex mixtures such as polluted air and exhaled breath.

A very important point to appreciate is that only a few reagent ion species are suitable for SIFT-MS analyses of air and breath. It turns out that $\mathrm{H}_{3} \mathrm{O}^{+}, \mathrm{NO}^{+}$and $\mathrm{O}_{2}{ }^{+}$are most suitable, because these ions do not react rapidly with the major components of air and breath viz. $\mathrm{N}_{2}, \mathrm{O}_{2}, \mathrm{H}_{2} \mathrm{O}, \mathrm{CO}_{2}$ and $\mathrm{Ar}$; this was revealed by previous detailed SIFT studies, many in the UK, of the ion chemistry relating to the terrestrial atmosphere. ${ }^{17}$ For SIFT-MS, detailed knowledge is required of the kinetics of the ion-molecule reaction processes occurring when $\mathrm{H}_{3} \mathrm{O}^{+}, \mathrm{NO}^{+}$and $\mathrm{O}_{2}{ }^{+}$reagent ions react with the wide variety of organic molecules that are present in biogenic samples. Without this knowledge, the recognition of composite trace components of complex matrices such as exhaled breath and the accurate quantification of the individual compounds cannot be achieved. This knowledge has been acquired by numerous studies, mostly in Keele and Prague, of the reactions of these three reagent ions with many volatile organic compounds, VOCs, including homologous series of alcohols, aldehydes, ketones and other compounds, as listed in Table 1. It turns out that there are trends in reactivity that, 


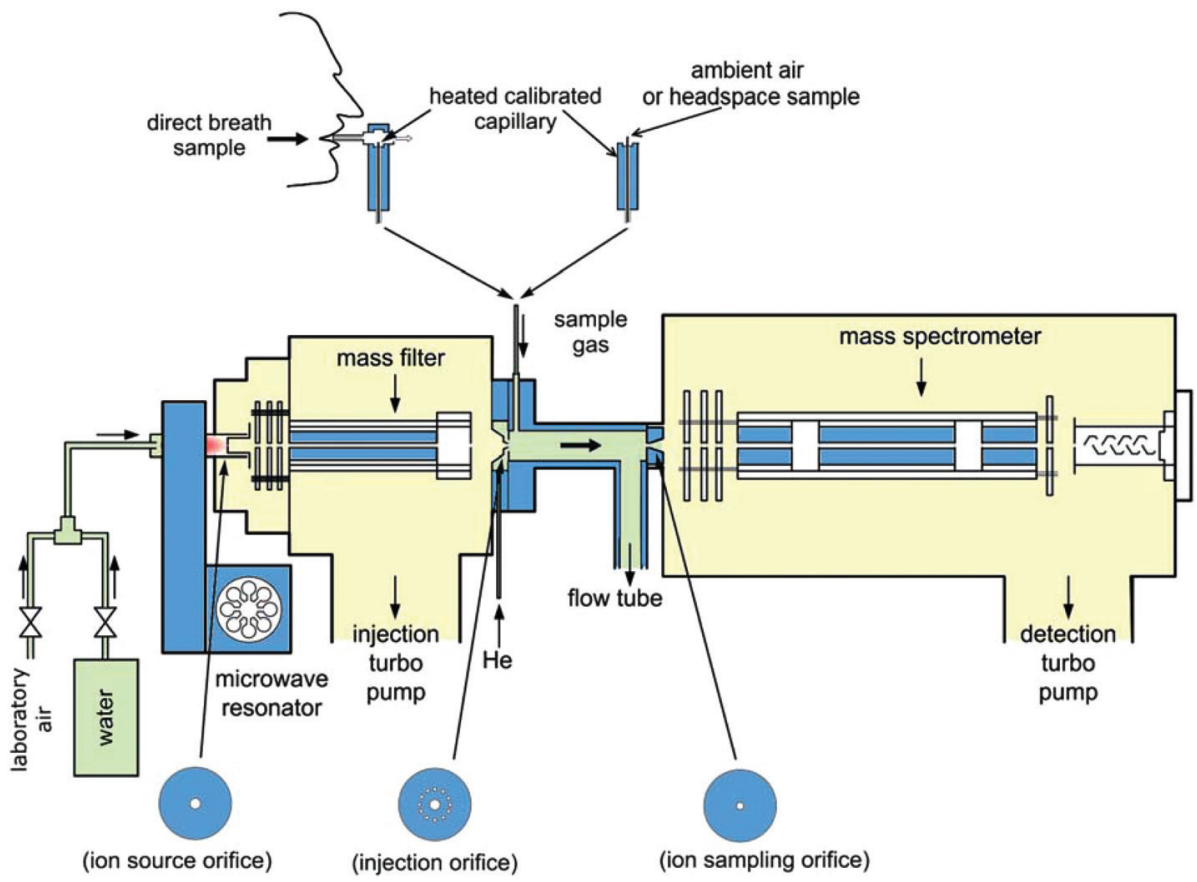

Fig. 2 A schematic diagram of the Profile 3 SIFT-MS instrument showing the microwave discharge ion source, injection mass filter and the three metal discs to which ion current can be measured and which support the orifices through which (i) ions pass from the ion source into the injection mass filter, (ii) mass selected reagent ions enter the flow tube reactor, (iii) reagent and product ions pass from the carrier gas/reactor into the analytical quadrupole mass spectrometer. Both direct sampling of ambient air and exhaled breath into the instrument and sampling of breath collected into bags and of liquid headspace can be achieved. Reproduced with permission from RSC from ref. 28.

Table 1 Processes that occur in the bimolecular and termolecular reactions of $\mathrm{H}_{3} \mathrm{O}^{+}$and $\mathrm{NO}^{+}$ions with various classes of organic compounds

\begin{tabular}{|c|c|c|}
\hline Compounds & $\mathrm{H}_{3} \mathrm{O}^{+}$reactions ${ }^{a}$ & $\mathrm{NO}^{+}$reactions ${ }^{a}$ \\
\hline Alcohols $^{35}$ & $\mathrm{MH}^{+} ;(\mathrm{M}-\mathrm{OH})^{+}$ & $(\mathrm{M}-\mathrm{H})^{+} ;(\mathrm{M}-\mathrm{OH})^{+}$ \\
\hline Diols $^{36}$ & $\mathrm{MH}^{+} ;(\mathrm{M}-\mathrm{OH})^{+}$ & $(\mathrm{M}-\mathrm{H})^{+} ;(\mathrm{M}-\mathrm{OH})^{+}$ \\
\hline Saturated aldehydes ${ }^{38,39}$ & $\mathrm{MH}^{+} ;(\mathrm{M}-\mathrm{OH})^{+}$ & $(\mathrm{M}-\mathrm{H})^{+}$ \\
\hline Unsaturated aldehydes ${ }^{38,39}$ & $\mathrm{MH}^{+}$ & $(\mathbf{M}-\mathrm{H})^{+} ; \mathbf{N O}^{+} \mathbf{M}$ \\
\hline Carboxylic acids ${ }^{40^{\circ}}$ & $\mathrm{MH}^{+} ;(\mathrm{M}-\mathrm{OH})^{+}$ & $\mathbf{N O}^{+} \mathbf{M} ;(\mathbf{M}-\mathrm{OH})^{+}$ \\
\hline Esters $^{40}$ & $\mathrm{MH}^{+} ;(\mathrm{M}-\mathrm{OR})^{+}$ & $\mathrm{NO}^{+} \mathbf{M} ;(\mathrm{M}-\mathrm{OR})^{+}$ \\
\hline Amines ${ }^{43,44}$ & $\mathrm{MH}^{+} ;(\mathrm{M}-\mathrm{H})^{+} ;(\mathrm{M}-\mathrm{R})^{+}$ & $\mathrm{M}^{+\bullet} ;(\mathrm{M}-\mathrm{H})^{+} ;(\mathrm{M}-\mathrm{R})^{+}$ \\
\hline Alkanes ${ }^{45,46}$ & $\mathrm{H}_{3} \mathrm{O}^{+} \mathrm{M}$ & $(\mathrm{M}-\mathrm{H})^{+}$ \\
\hline Alkenes ${ }^{45,46}$ & $\mathrm{MH}^{+}$ & $\mathrm{M}^{+}$ \\
\hline Monoterpenes ${ }^{47,48}$ & $\mathrm{MH}^{+},(\mathrm{M}-\mathrm{R})^{+}$ & $\mathrm{M}^{+\bullet} ;(\mathrm{M}-\mathrm{R})^{+}$ \\
\hline Aliphatic halocarbons ${ }^{49,50}$ & $\mathrm{MH}^{+}, \mathbf{H}_{3} \mathbf{O}^{+} \mathbf{M},(\mathrm{M}-\mathrm{X})^{+},(\mathrm{M}-\mathrm{X}) \mathrm{OH}^{+}$ & $(\mathrm{M}-\mathrm{X})^{+} ; \mathrm{M}^{+\cdot} ; \mathbf{N O}^{+} \mathbf{M}$ \\
\hline Aromatic hydrocarbons ${ }^{45,46}$ & $\mathrm{MH}^{+}$ & $\mathrm{M}^{+\bullet}$ \\
\hline
\end{tabular}

${ }^{a}$ The reactant molecules are designated as $\mathrm{M}$, protonated molecules as $\mathrm{MH}^{+}$and parent radical cations as $\mathrm{M}^{+\bullet}$. $\mathrm{NO}^{+} \mathrm{M}$ and $\mathrm{H}_{3} \mathrm{O}^{+} \mathrm{M}$ are adduct ions formed largely in ternary association reactions. ${ }^{21,55}$ Product ions resulting from the loss of neutral fragments are indicated by bracketing, for example $(\mathrm{M}-\mathrm{OH})^{+}$indicates the loss of $\mathrm{OH}$ from the nascent ion; the $\mathrm{R}$ are alkyl radicals; the $\mathrm{X}$ are halogen atoms, either $\mathrm{Cl}$ or $\mathrm{Br}$. Note that $\mathrm{NO}^{+}$is unreactive with $\mathrm{CH}_{3} \mathrm{OH}, \mathrm{H}_{2} \mathrm{~S}, \mathrm{HCN}$ and $\mathrm{NH}_{3}$.

when recognised, greatly facilitate identification of unknown trace compounds in SIFT-MS analyses.

The reactions of $\mathrm{H}_{3} \mathrm{O}^{+}$reagent ions are sometimes relatively simple, proton transfer producing $\mathrm{MH}^{+}$nascent ions as indicated by reaction (1). However, often the nascent $\mathrm{MH}^{+}$ions partially fragment with the loss of an $\mathrm{H}_{2} \mathrm{O}$ molecule, as seen in Table 1. In a sense conversely, the SIFT-MS spectra reveal that hydration of both $\mathrm{H}_{3} \mathrm{O}^{+}$reagent ions and $\mathrm{MH}^{+}$product ions is very common when breath samples are being analysed (see below). The reactions of $\mathrm{NO}^{+}$reagent ions are varied with 
hydride ion transfer producing $(\mathrm{M}-\mathrm{H})^{+}$ions, hydroxide ion transfer producing $(\mathrm{M}-\mathrm{OH})^{+}$ions and adduct ion formation producing $\mathrm{NO}^{+} \mathrm{M}$ ions being commonly observed. The reactions of $\mathrm{O}_{2}{ }^{+}$reagent ions initially proceed via electron transfer generating $\mathbf{M}^{+\bullet}$ radical parent cations that usually fragment when $\mathrm{M}$ is polyatomic. To repeat, the understanding of and the kinetics data relating to these reaction processes is essential for the interpretation of SIFT-MS analytical spectra and is especially important for researchers developing and expanding the SIFT-MS analytical method. However, such expertise is not essential for scientific, clinical or technical personnel who are focused on routine analysis, since it is implicitly contained within the on-board kinetics library, the construction and structure of which is described and explained in recent papers. ${ }^{29,56}$ Much has been written on the details of the above analytical ion-molecule reaction processes in many research and review papers. ${ }^{13,17,21,57}$

A complicating effect, alluded to above, becomes obvious when using SIFT-MS to analyse humid samples, which is the appearance on the analytical spectra of hydrated reagent ions, especially $\mathrm{H}_{3} \mathrm{O}^{+}\left(\mathrm{H}_{2} \mathrm{O}\right)_{1,2,3}$ and $\mathrm{NO}^{+}\left(\mathrm{H}_{2} \mathrm{O}\right)_{1,2}$ cluster ions. These cluster ions are formed largely by helium-mediated three-body association reactions of the $\mathrm{H}_{3} \mathrm{O}^{+}$and $\mathrm{NO}^{+}$reagent ions with the abundant $\mathrm{H}_{2} \mathrm{O}$ molecules present in humid samples. A further complication is that the product ions can also become hydrated resulting in ions like $\mathrm{MH}^{+}\left(\mathrm{H}_{2} \mathrm{O}\right)_{1,2}$ and (M$\mathrm{H})^{+}\left(\mathrm{H}_{2} \mathrm{O}\right)_{1,2}$ and these hydrated ions must be considered as additional reagent and product ions and properly accounted for in the quantitative analysis of individual trace compounds. This phenomenon is accounted for in the more sophisticated SIFT-MS analysis described in two detailed publications ${ }^{32,58}$ that describe how accurate SIFT-MS analyses are obtained. This aspect and other interesting and unique features of SIFT-MS are discussed in detail in several research and review papers. ${ }^{4,21,28,29,59}$ A major issue complicating routine use of SIFT-MS for analyses of biological samples is the overlap of product ions resulting from different compounds at the same $\mathrm{m} / \mathrm{z}$ values. Whilst this has been overcome in individual cases either by using the most appropriate reagent ions for each analyte compound or by utilising differences in product ion signal ratios, ${ }^{56,60}$ these approaches are a challenge for nonchemists and there is a need for more developments of robust and simpler data analysis procedures.

\section{SIFT-MS instrumentation}

All generations of SIFT-MS instrument have essentially the same form. They consist of an ion source and ion selection (injection) quadrupole mass filter, a carrier gas flow tube reactor, a downstream analytical quadrupole mass spectrometer, a drive pump for the carrier gas and turbo pumps to maintain the quadrupole chambers at suitably low pressures. The size, cost and performance of the instrument largely depends on the performance of the quadrupoles, the length and diameter of the flow tube, the pumping speeds of the carrier gas drive pump and the turbo pumps, and the nature of the ion source. The ultimate sensitivity of the instrument as an analytical device depends on the achievable reagent ion count rates and consequently the product ion count rates, but these are also dependent on the choice of the of interdependent parameters such as the carrier gas and sample gas flow rates and the ion sampling orifice aperture sizes. Fig. 2 shows a schematic of Profile 3 SIFT-MS instrument that was developed and marketed in the UK. ${ }^{4,26}$ The detailed considerations of the analytical sensitivity and all the dependent parameters and variable are discussed in recent papers, especially the review paper. ${ }^{4}$ The limit of detection of the Profile 3 instrument is currently at 0.1 parts-per-billion by volume, ppbv, for one second of integration time of the product ions count rates, but this is being improved continuously with the expectation of an order-of-magnitude improvement as the engineering aspects of SIFT-MS instrumentation and understanding of the associated physics and ion chemistry grows. However, by lowering the limit of detection the chance of significant overlap of analyte ions at the same $\mathrm{m} / \mathrm{z}$ with fragment ions of other compounds in the matrix or background air increases and this will have to be considered in future developments of advanced SIFT-MS instruments. It is self-evident that a desirable goal is to produce small, low cost instruments with improved performance that can readily be moved and utilized in different locations. Remarkable strides have been made towards these objectives, notably in the UK, by reducing the size of the initial laboratory-based instruments, initially at about $2000 \mathrm{~kg}$, to the production of the much smaller, portable Profile 3 instrument at $120 \mathrm{~kg}$. ${ }^{4}$ This has required that the reactor flow tube length was shortened from about $140 \mathrm{~cm}$ down to $5 \mathrm{~cm}$.

\section{The current SIFT-MS instrument}

The performance of the UK Profile 3 SIFT-MS instruments and the quality of trace gas analyses obtained in a variety of applications in the UK are illustrated by the data presented in several research and review papers by the teams at Keele, ${ }^{29,61-66}$ Prague, ${ }^{67-73}$ Thunder Bay, Canada, ${ }^{74-77}$ Imperial College London $^{78-90}$ and the University of The West of England. ${ }^{91,92}$ Major application have been in physiology and medicine through the analyses of exhaled breath and the headspace of biological fluids such as urine and mammalian and bacterial cell cultures, ultimately intended as a contribution to clinical diagnosis and therapeutic monitoring. Other areas of applications of Profile 3 include environmental science, food science and analyses of fumes of explosives as summarised in Table 2 later together with appropriate references.

SIFT-MS as a trace gas ambient analytical technique was initially conceived and developed at Keele by the authors of this paper ${ }^{9,30,93}$ benefiting from the earlier development of the SIFT technique by the Birmingham group, ${ }^{10,14}$ subsequently with significant contribution by the Aberystwyth group. ${ }^{94,95}$ The growing use and application of SIFT-MS in the UK is seen in the geographical distribution of the groups who are now benefiting from the exploitation of this analytical method seen 
Table 2 Areas of application SIFT-MS

Biomedical

Physiology

Breath

Urine

Skin

Halitosis

Addiction and substance abuse

Renal failure

Bacterial infection

Cancer

Breath

Urine

Diabetes

Inflammatory bowel disease

Food science

Environment; health and safety

Security

in Fig. 1. The Profile 3 is its latest manifestation and it is this instrument that is the focus of this paper by illustrating its unique power in directly analysing the humid media mentioned above. When the volatile compounds emitted by such humid media can be analysed accurately in real time at appropriately low concentration, then analyses of less humid ambient air are relatively straightforward.

Other models of SIFT-MS instruments have been produced in New Zealand and marketed by the Syft Company as the Voice 100/200 instruments. ${ }^{159,168}$ These have also been used for breath analysis, ${ }^{169-172}$ monitoring of environmental pollutants, ${ }^{157-160}$ warfare agents studies $^{173}$ and in food science. ${ }^{140-152,174}$ The main commercial application of Voice 200 instruments is in screening of containers in ports for illicit substances and for toxic gases in order to protect the health and safety of customs officials. ${ }^{5,164}$
Influence of diet on breath volatiles ${ }^{69,96-98}$

Ethanol metabolism ${ }^{99-101}$

Oral microflora and difference between nasal and oral exhalations ${ }^{102,103}$ Exercise $^{103,104}$

Ketones in urine $\mathrm{e}^{105,106}$

Volatile markers of ovulation in urine $\mathrm{e}^{107,108}$

Release of volatile compounds by skin ${ }^{109}$

Odorous breath compounds ${ }^{61}$

Breath composition after antabuse ingestion ${ }^{110}$

Compounds in tobacco and cannabis smoke $e^{9,111,112}$

Breath biomarkers of kidney dysfunction ${ }^{54,113-115}$

Total body water monitoring ${ }^{116-119}$

Breath biomarkers of infection in cystic fibrosis ${ }^{120-124}$

Alveolar lavage ${ }^{125}$

Bacterial cultures ${ }^{61,126,127}$

Diagnostic breath biomarkers ${ }^{128,129}$

Tissue cell cultures

Volatile compounds released by cancer cell lines ${ }^{130,131}$

Volatile biomarkers of cancer and infection in urine ${ }^{132,133}$

Breath biomarkers ${ }^{134-136}$

Breath biomarkers of disease activity ${ }^{68}$

Quantification of aroma compounds in fermentation ${ }^{137}$ Oil quality ${ }^{138,139}$

Food flavour analyses ${ }^{137,140-153}$

Volatile compounds emitted by fruits and vegetables ${ }^{140}$

Volatile organic compounds related to sensory qualities ${ }^{140}$

Biological monitoring ${ }^{154}$

Exhaust gases ${ }^{155,156}$

Atmospheric pollutants ${ }^{157-163}$

Monitoring of cargo containers ${ }^{164}$

Detection of volatile markers of explosives ${ }^{165-167}$ Fumes of explosions ${ }^{166}$

\section{Quantitative analyses by SIFT-MS}

The analysis by SIFT-MS of trace gases in air invariably begins by obtaining a so-called full scan (FS) spectrum in which one of the reagent ion species $\left(\mathrm{H}_{3} \mathrm{O}^{+}, \mathrm{NO}^{+}, \mathrm{O}_{2}^{+}\right)$is selected and injected into the helium carrier gas and the air is sampled into the thermalized ion swarm at an acceptable flow rate. This usually results in a complex FS spectrum of reagent and product ions that can both identify and allow the quantification of the neutral trace compounds in the sample. Sample FS spectra are shown in Fig. 3 that were obtained for the analysis of the humid headspace of a fungal culture ${ }^{175}$ using separately $\mathrm{H}_{3} \mathrm{O}^{+}$, $\mathrm{NO}^{+}$and $\mathrm{O}_{2}^{+}$reagent ions. The challenge is then to identify the trace neutral compounds present in the sample via their characteristic product ions at particular $\mathrm{m} / \mathrm{z}$ values. Commonly met product ions are easily recognised if their 

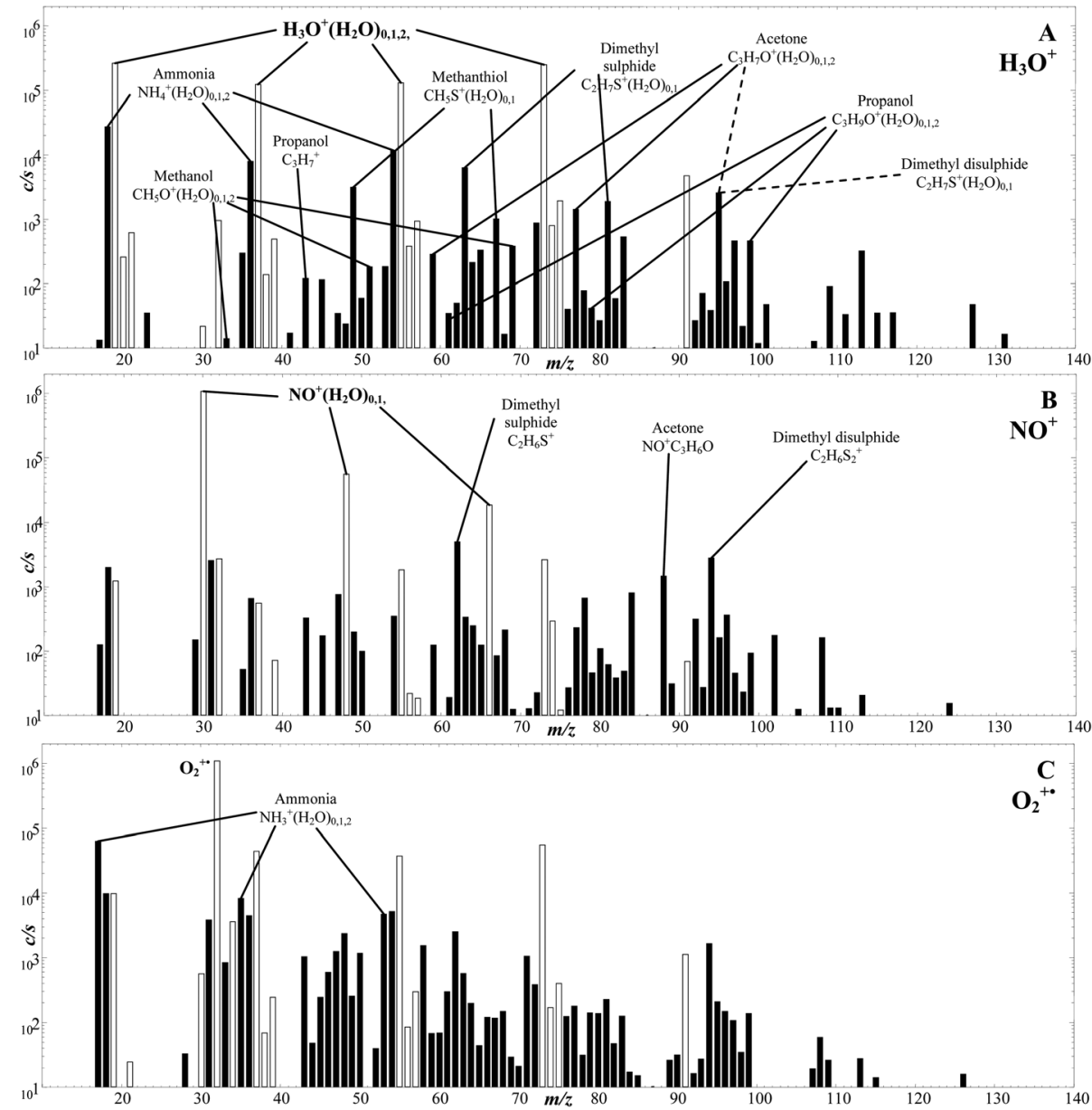

Fig. 3 .SIFT-MS full scan mass spectra (ion mass-to-charge ratio, $m / z$, plotted against the ion counts-per-second, $c / s$ ) showing the compounds present in the headspace of $A$. fumigatus (AF) cultures when analysed employing $\mathrm{H}_{3} \mathrm{O}^{+}$(A), $\mathrm{NO}^{+}(\mathrm{B})$ and $\mathrm{O}_{2}^{+{ }^{+}}(\mathrm{C})$ as the reagent ion. The cultures were incubated at $37{ }^{\circ} \mathrm{C}$ for $72 \mathrm{~h}$ prior to the headspace analysis. The product ions of the trace compounds produced by AF are indicated as filled bars on the mass spectra. Note that small fractions of the hydronium ion and its hydrates $\left(\mathrm{H}_{3} \mathrm{O}^{+}\right)_{0,1,2,3}$ at $m / z 19,37,55,73$ are also present in the $\mathrm{NO}^{+}$and $\mathrm{O}_{2}{ }^{+\cdot}$ spectra (B and $\mathrm{C}$ respectively), which are shown with open bars. Reproduced with permission from RSC from ref. 175.

signal levels are sufficiently high and then a quick quantitative analysis of the neutral analyte trace molecules can be obtained by exploiting the SIFT-MS kinetics library; some such common compounds are shown on the spectra in Fig. 3. For product ion at low signal levels, multiple FS spectra can be accumulated to facilitate analysis and improve precision. Some ions cannot readily be recognised and then, as a first stage in the analysis, ion-chemical intuition is needed that can be acquired by studying the extensive kinetics data accumulated on ion-molecule reactions that is reported and discussed in many SIFT-MS-related papers. $^{35,36,38-40,42-47,49-51,56,176-184}$ Comparing FS spectra for all three reagent ions provides assistance in recognising the unknown neutral compounds in the air mixture given the different ion chemistries involved. Significantly, these spectral data are obtained rapidly in real time avoiding the likely disturbing effects that can result from sample collection and manipulation. Numerous such studies have been carried out that are providing much data of interest in the biological and environmental sciences. ${ }^{35,36,38-40,42-47,49-51,56,176-184}$
When the $\mathrm{m} / \mathrm{z}$ values of characteristic product ions are recognised in the FS spectrum, more accurate analysis of the trace neutral compounds is achieved using the multiple ion monitoring (MIM) mode of SIFT-MS. In this approach, the $\mathrm{m} / \mathrm{z}$ values of all the reagent and characteristic product ions for each trace compound are entered into the analytical software and a rapid switch/dwell/count procedure for each of the ions is used to accumulate the reagent ion/product ion signal count rates that provide the trace neutral compounds quantifications. This procedure can be very rapid, which allows temporal changes in the concentrations of trace compounds to be followed in real time, a good example being the definition of the concentration profiles of several exhaled breath compounds simultaneously obtained from consecutive single breath exhalation/inhalation cycles, as seen in Fig. 4, which shows the reproducibility of the data acquired by on-line, real time SIFT-MS analyses of single breath exhalations. They also show the very wide range of compound concentrations that is accessible in single exhalations from those for water vapour 


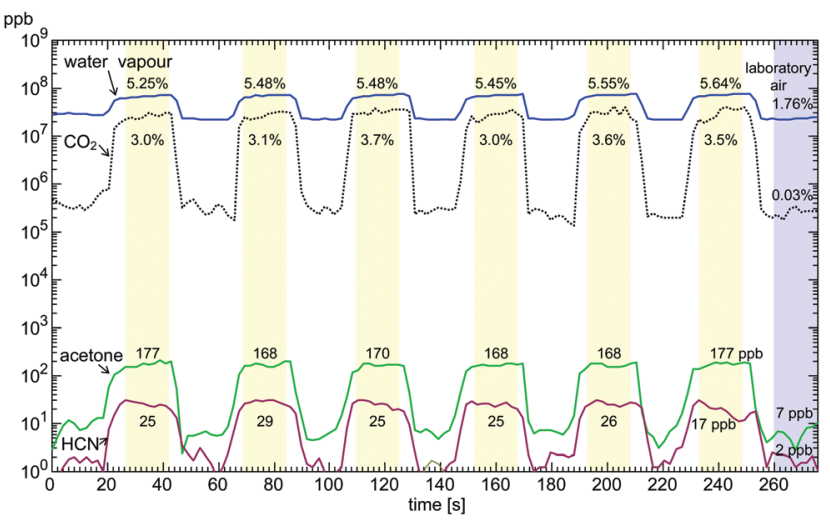

Fig. 4 Plots of the time profiles and the derived breath concentrations of water vapour and $\mathrm{CO}_{2}$ (in \%) and acetone and $\mathrm{HCN}$ (in parts-perbillion by volume, ppb), obtained using the Profile 3 SIFT-MS instrument in the multi ion monitoring, MIM, mode, for six sequential breath exhalations by one volunteer during the time period indicated in seconds. These data show the remarkable consistency in the derived concentrations of these compounds in the alveolar regions of the exhalations, as indicated by the shaded portions. Also indicated to the right are the laboratory air levels of these compounds. Reproduced from ref. 28, with permission from RSC.

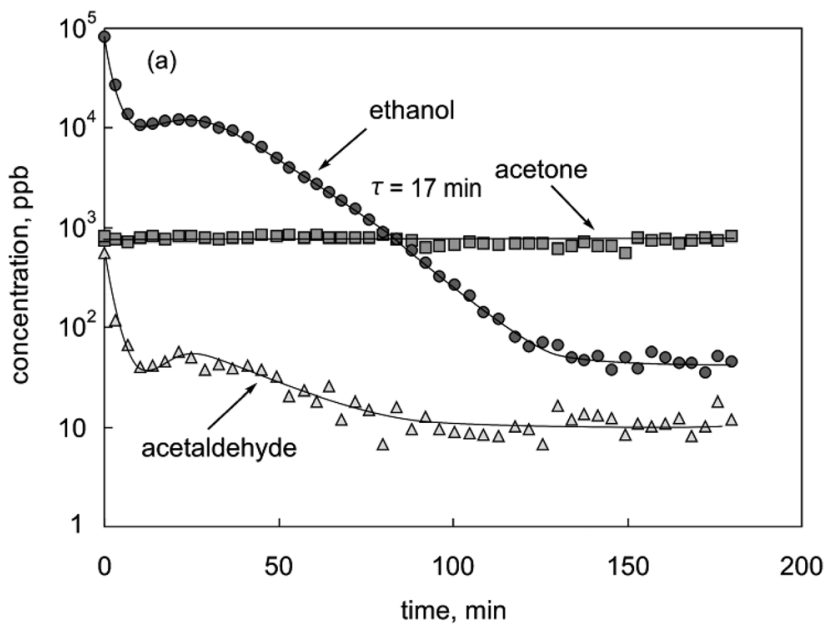

Fig. 5 The variation of the concentration of ethanol and its metabolite acetaldehyde, and the endogenous acetone (in parts-per-billion by volume, $\mathrm{ppb}$ ) in mouth-exhaled breath as a function of time following the ingestion by a healthy volunteer of $7.5 \mathrm{~mL}$ of ethanol dissolved in $250 \mathrm{~mL}$ of water. Also given is the exponential time constant $(\tau$, in $\mathrm{min}$ ) for the exhaled ethanol concentration as obtained from the slope of the semi-log plot. Reproduced from ref. 99 with permission form Wiley.

(a unique feature of SIFT-MS ${ }^{185}$ ) and carbon dioxide, ${ }^{186}$ both at the few percent level, to the trace compounds acetone and hydrogen cyanide at the few ppbv level. Ipso facto, temporal variations in the concentrations of specific trace compounds can be followed exemplified by the breath concentration decay curves of ethanol and its metabolite acetaldehyde shown in Fig. 5. These well-defined decay curves were obtained by analysing exhaled breath every minute or so for a period of about 3 hours following the ingestion by an individual of a small amount of ethanol. ${ }^{99}$ Clearly, on-line real time analysis is very acceptable in the clinical environment, since it is a simple, non-invasive procedure, the data being immediately available to the clinician/health worker. Similarly, the temporal changes in the concentrations of particular volatile biomarker compounds in exhaled breath have applications in pharmacokinetics and the tracking of drug-related compounds in the therapy clinic.

Many related studies imping on physiology and medicine have been carried out using Profile 3 instruments, principally in the UK, Czech Republic and Canada. They include the modification of breath biomarkers due to dietary intake ${ }^{69,96}$ and exercising, ${ }^{103}$ headspace analyses of several mammalian ${ }^{128,130,131,187}$ and bacterial cell cultures ${ }^{64,126,188,189}$ and fungal $^{175}$ cultures, and volatile compounds released from urine sampled during ovulation, ${ }^{107,108}$ just to mention a few; refer to Table 2 for further applications and references. It is not appropriate to attempt to discuss many of these studies in detail in this short review; rather, a few case reports will be given in the penultimate section of this paper that demonstrate the special value of SIFT-MS for ambient gas analysis.

\section{Principle of the flowing afterglow mass spectrometry, FA-MS, analytical method}

A SIFT-MS FS spectrum obtained using $\mathrm{H}_{3} \mathrm{O}^{+}$reagent ions when humid air or exhaled breath is introduced into the helium carrier gas immediately reveals the appearance of $\mathrm{H}_{3} \mathrm{O}^{+}\left(\mathrm{H}_{2} \mathrm{O}\right)_{1,2,3}$ hydrate cluster ions as major fraction of the total ions (see Fig. 3a for instance). Further to this, the ${ }^{2} \mathrm{H}$ (deuterium, D), ${ }^{17} \mathrm{O}$ and ${ }^{18} \mathrm{O}$ isotopologue variants of these cluster ions are present (more clearly seen in Fig. 6a for D-enriched water), the peak relative levels of these isotopologues are determined by the fractions of each isotopic variant of the water molecules $\left(\mathrm{H}_{2} \mathrm{O}, \mathrm{HDO}, \mathrm{H}_{2}{ }^{17} \mathrm{O}, \mathrm{H}_{2}{ }^{18} \mathrm{O}\right)$ comprising the water vapour introduced into the system. The natural abundances of these isotopic variants in local water are known and the distribution of the isotopologue cluster ions is seen to be in accordance with these abundances. ${ }^{119,190,191}$

These FS observations immediately suggested that the isotopic content of water vapour, especially that of the most abundant HDO, might be determined quickly and directly from the relative peak heights of the isotopologue ions, avoiding complex sample preparation that is used in conventional methods for deuterium isotope analysis. ${ }^{192}$ Encouragingly, pilot experiments at Keele using known admixtures of heavy water, $\mathrm{D}_{2} \mathrm{O}$, in water, $\mathrm{H}_{2} \mathrm{O}$, showed that the $\mathrm{HDO}$ content of the water vapour above the enriched liquid could be determined with precision and accuracy when the ion chemistry and physics of isotope exchange in the relevant ion-molecule reactions is understood, as is outlined below. ${ }^{193}$ This provided the opportunity to study in real time the deuterium content of the 

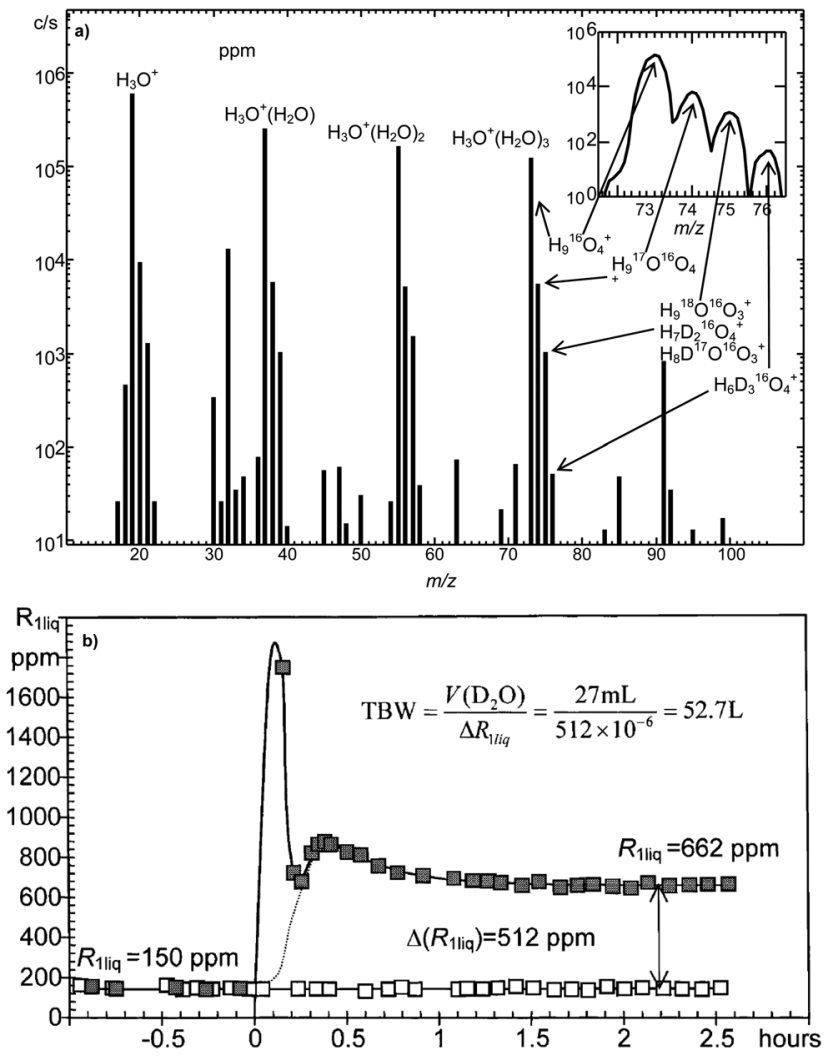

Fig. 6 (a) The SIFT-MS mass spectrum (counts per second, c/s against ion mass-to-charge ratio, $\mathrm{m} / \mathrm{z}$ ) obtained as the water vapour from $\mathrm{D}_{2} \mathrm{O}^{-}$ enriched water is flowed into the helium carrier gas. The observed isotopologues of the trihydrate of $\mathrm{H}_{3} \mathrm{O}^{+}$are indicated in the inset. Reproduced with permission from ACS from ref. 194. (b) Determination of body water deuterium abundance, $R_{1 \text { liq, }}$ expressed in parts per million (ppm) of hydrogen obtained from single breath exhalations, and the derived total body water, TBW, in litres (L) obtained from the equilibrium value of $R_{\text {1liq }}$ some $2 \mathrm{~h}$ following the ingestion of $27 \mathrm{~mL}$ of $\mathrm{D}_{2} \mathrm{O}$. The open squares refer to the control volunteer (no $\mathrm{D}_{2} \mathrm{O}$ ingestion) and the filled squares to the breath of the volunteer (body weight $92 \mathrm{~kg}$ ) both before and after the ingestion of the $\mathrm{D}_{2} \mathrm{O}$ (at time zero). Reproduced with permission from Wiley from ref. 191.

water present in biological fluids, including exhaled breath and urine.

The physical and ion chemical principles underpinning this novel analytical method are as follows: a swarm of $\mathrm{H}_{3} \mathrm{O}^{+}$ precursor ions is created in the helium carrier of the SIFT-MS instrument by ion injection in the usual way. The water vapour evolving from natural water or D-enriched water (or that present in exhaled breath) is sampled into the carrier gas where the $\mathrm{H}_{3} \mathrm{O}^{+}$precursor ions react with the $\mathrm{H}_{2} \mathrm{O}, \mathrm{HDO}$, $\mathrm{H}_{2}{ }^{17} \mathrm{O}$ and $\mathrm{H}_{2}{ }^{18} \mathrm{O}$ molecules in the water vapour sample. The signal levels of D-containing isotopologues associated with the $\mathrm{H}_{3} \mathrm{O}^{+}\left(\mathrm{H}_{2} \mathrm{O}\right)_{0,1,2,3}$ ions are all enhanced when D-enriched water vapour is the sample (see Fig. 6a). Of special interest, for the thermodynamic reasons explained in detail in a previous publication, ${ }^{193}$ is the trihydrate ion, $\mathrm{H}_{3} \mathrm{O}^{+}\left(\mathrm{H}_{2} \mathrm{O}\right)_{3}$ at $m / z=73$, and its isotopic variants $\mathrm{H}_{8} \mathrm{DO}_{4}{ }^{+}$and $\mathrm{H}_{9}{ }^{17} \mathrm{OO}_{3}{ }^{+}$at $\mathrm{m} / \mathrm{z}=74$ and $\mathrm{H}_{9}{ }^{18} \mathrm{OO}_{3}{ }^{+}$at $m / z=75$. The isotopic abundance of ${ }^{17} \mathrm{O}$ (typically
0.0380) and ${ }^{18} \mathrm{O}$ (typically 0.200 ) in local water are known. Thus, by using the signal level of $\mathrm{H}_{9}{ }^{18} \mathrm{OO}_{3}{ }^{+}$at $\mathrm{m} / z=75$ as a reference, the fraction of the isotopologue ions $\mathrm{H}_{9}{ }^{17} \mathrm{OO}_{3}{ }^{+}$to the total ion signal at $\mathrm{m} / z=74$ can be calculated and adjusted; then a measurement of the $m / z 74 / 75$ ion signal ratio using the downstream mass spectrometer provides the fractional deuterium abundance in the water vapour sample. ${ }^{194}$ Correction is made for the differences in evaporation rates of $\mathrm{H}_{2} \mathrm{O}$ and $\mathrm{HDO}$ from the liquid water samples that, of course, depend on the water temperature; in the case of breath analysis, the temperature at the lung blood/breath interface (body core temperature) is taken. This new method of $\mathrm{D}$ quantification (assay) was proven by careful experiments using standard mixtures of D-enriched water. ${ }^{190}$

Of particular interest in renal medicine and body composition, as explained by the local nephrology consultant at the University Hospital of North Staffordshire (S. J. Davies), is the rapid measurement of total body water, TBW, especially in patients suffering from chronic kidney disease who suffer from serious water overload. The standard method of measuring TBW is the isotopic dilution method. This involves the ingestion of a known (small) amount of $\mathrm{D}_{2} \mathrm{O}$, which rapidly converts to $\mathrm{HDO}$ in the large $\mathrm{H}_{2} \mathrm{O}$ water pool in the body, and the subsequent analysis of the equilibrium HDO content of blood and/or urine. The main reason why this very safe method is not used more frequently is the time consuming and complex method of measuring $\mathrm{D}$ enrichment of the body fluids, ${ }^{192}$ which usually requires that batch samples are sent to reference laboratories for analysis consequently involving delays in obtaining results. Thus, following the above encouraging laboratory SIFT-MS studies, pilot experiments were conducted to measure TBW in several healthy volunteers using the isotope dilution method and the rapid, on-line direct SIFT-MS analysis of the D content of the water vapour contained in single breath exhalations.

These pilot measurements were carried out using an early version of SIFT-MS and demonstrated the efficacy of this analytical method. ${ }^{119,191,195,196}$ This offered the tantalizing prospect of immediate non-invasive measurement of TBW at the bedside and, alternatively, the measurement of the deuterium content of the equilibrated headspace above a body fluid such as plasma that can be collected and stored in a sealed container for later off-line analysis. However, the use of the early SIFT-MS instrument provided data that was not at the desirable accuracy and precision for serious clinical work except by adopting multiple measurement procedures. To achieve the required accuracy and precision a novel type of ion flow tube device was developed termed flowing afterglow mass spectrometry (FA-MS). This is a simpler instrument that is dedicated only to the measurement of the HDO content of water vapour, unlike the more versatile SIFT-MS instruments. The FA-MS instrument is smaller and more readily portable. It dispenses with the upstream mass filter of the SIFT-MS (see Fig. 2) and the $\mathrm{H}_{3} \mathrm{O}^{+}$precursor ions are created directly by a weak microwave discharge through the flowing helium/moist air mixture. This results in much larger count rates of the 
analytical $\mathrm{H}_{3} \mathrm{O}^{+}\left(\mathrm{H}_{2} \mathrm{O}\right)_{3}$ ions and its isotopic variants that, via statistics, immediately increases the accuracy and precision of the measurement of the HDO content of the water sample. These important considerations have been thoroughly discussed in previous papers. ${ }^{190,194}$

An example of the raw data describing the time evolution of the $\mathrm{D}$ content of exhaled breath following $\mathrm{D}_{2} \mathrm{O}$ ingestion is shown in Fig. 6b with explanatory notes in the caption. With FA-MS the $\mathrm{HDO} / \mathrm{H}_{2} \mathrm{O}$ molecule ratio in single breath exhalations and urine/blood headspace aspirations can be obtained to about $1 \%$ precision and accuracy. ${ }^{190}$ Thus, when this ratio is measured following the ingestion of an accurate mount of $\mathrm{D}_{2} \mathrm{O}$, typically $0.3 \mathrm{ml} \mathrm{kg}^{-1}$ body weight, the $\mathrm{TBW}$ value can be determined to an accuracy of a few hundred $\mathrm{mL}$ in most cases, which is adequate for most clinical purposes. One of the advantages of this method is that multiple samples can be taken in rapid succession enabling the determination of the kinetics of HDO equilibration throughout the TBW (Fig. 6b). Typically, it is found that full equilibration occurs within 90 minutes within the TBW following oral ingestion of $\mathrm{D}_{2} \mathrm{O}{ }^{119}$ In a series of clinical studies undertaken to establish the validity of the above analytical method, it was shown that measurement of TBW is both feasible and acceptable to patients attending the dialysis clinic. ${ }^{117,197}$ These cited references indicate the great potential of FA-MS in determining TBW of healthy persons and ill-patients alike. Further studies are currently in progress to establish the value of the FA-MS approach to monitoring body composition and to support intervention to minimise the complications of water overload in dialysis patients. It is now envisaged that optical absorption spectroscopy could be used to develop miniature point-of-care instruments for isotopic analyses of water vapour in exhaled breath.

\section{Brief reports on selected research programmes involving SIFT-MS}

The creation of this powerful ambient analysis technique provided the means to promote the wide variety of research areas listed in Table 2, the results of which are detailed in the cited references. Here, just a few topics are selected for brief review that illustrate the unique contribution that the exploitation of SIFT-MS is making to physiology and medicine via detailed breath analysis and associated studies of volatile compounds released by in vitro cultures of mammalian and bacterial cells. The focus is on the work carried out by research groups in the UK in collaboration with the closely associated group in Prague using the SIFT-MS instruments developed and manufactured entirely in the UK. Before starting, it is pertinent to note that analytical studies involving the wide range of volatile compounds released from biological fluids could not be pursued without parallel and continuing experiments to accumulate the large amount of kinetics data on ion-molecule reactions that are essential to build the aforementioned kinetics library for SIFT-MS. The results of these kinetics studies are reported in several research papers, as summarised in some recent reviews. ${ }^{4,28}$ Such work must be seen as integral part of the time and intellectual effort that has been required to develop the SIFT-MS and FA-MS analytical methods.

\section{Breath analysis involving healthy volunteers}

Breath analysis is a relatively new area of experimental science and physiology and medicine. When the SIFT-MS analytical method was proved to be accurately quantitative and the simplicity of its application to breath analysis was demonstrated, a programme was initiated to study the reference ranges (population concentration distributions) of the common metabolites in exhaled breath of the healthy population. This is an essential prelude to studies of abnormal concentrations of metabolites in exhaled breath of patients with specific disease or infections. Data acquisition of the kind illustrated in Fig. 4 can be rapid and the exhaled breath of as many as 70 volunteers has been analysed for several metabolites in a single morning. ${ }^{72}$ The breath of healthy cohorts can be analysed over periods of days or months and by such longitudinal (interindividual variations) studies the reference ranges of several common breath metabolites have been constructed by work at Keele, Prague and the Silsoe Research Institute (C. Turner) in the UK. ${ }^{198-202}$ Examples of the data obtained are shown in Fig. 7 (reproduced from ref. 203); these are immensely valuable as guides to subsequent studies. Similarly, variations in breath metabolite concentrations within given persons (intra-individual variations) have been carried out, ${ }^{204}$ which reveal temporal and diurnal variations and the influence of diet, the last being dramatically revealed by the study of breath acetone following a ketogenic diet. ${ }^{69}$

Another important phenomenon, so significant in breath research, is the recognition that mouth-exhaled breath can be seriously contaminated with the volatile compounds generated in the oral cavity by the action of bacteria or salivary enzymes. ${ }^{102,103}$ To reveal which compounds are orally generated, the simplicity of real-time breath analysis by SIFT-MS is again exploited by directly analysing separately the breath exhaled via the nose and mouth. Such studies immediately reveal, for example, that ammonia and ethanol are largely produced in the oral cavity whereas acetone and isoprene are purely generated systemically. ${ }^{61,63}$ Breath analysis research exploiting SIFT-MS vigorously continues in the UK; this includes studies at the Open University (C. Turner) ${ }^{205-209}$ of the exhaled breath of cattle ${ }^{210}$ and horses with colic ${ }^{211}$ and concomitant breath and skin analysis for monitoring blood glucose concentration in diabetes, ${ }^{212,213}$ and interesting investigations at Nottingham University of the relation between exhaled breath and blood levels of volatile compounds, notably acetone. ${ }^{170}$ Also the Voice 200 instruments are increasingly becoming used for breath analysis. ${ }^{169,171,172,214}$

\section{Volatile compounds emitted by in vitro cultures of mammalian and bacterial cells}

The hope and expectation for many years has been that volatile compounds released by living cells cultivated in vitro, for 


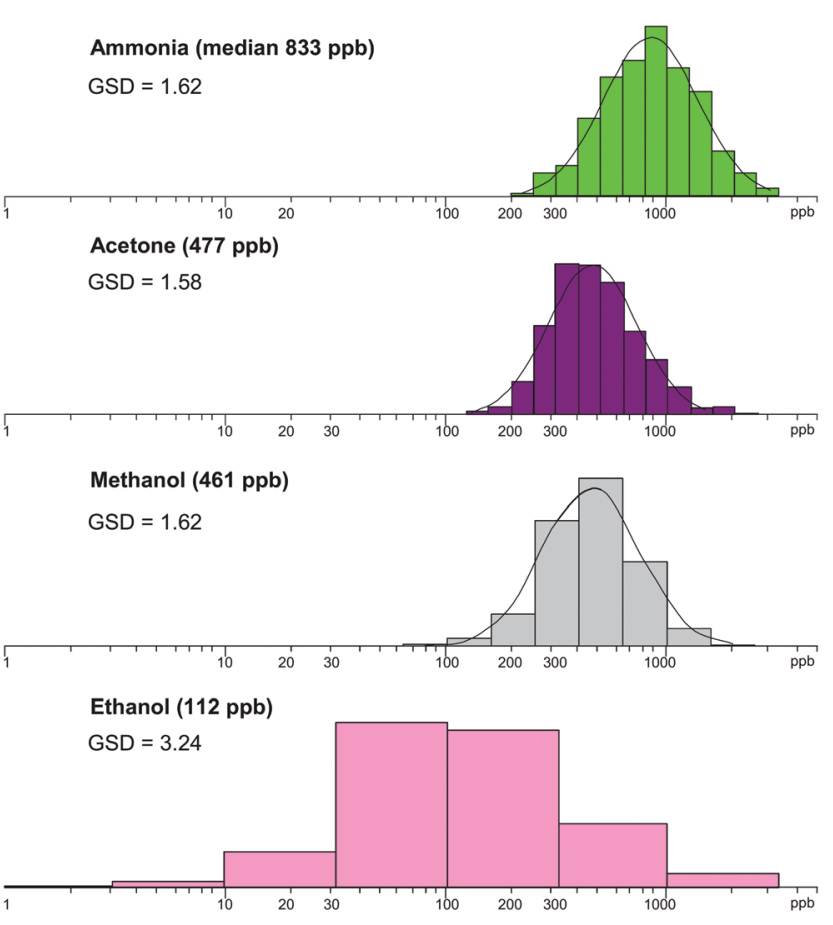

Isoprene (106 ppb) GSD $=1.65$

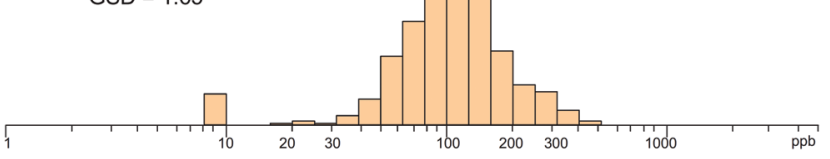

Fig. 7 Distributions of the five most prominent trace metabolites present in the exhaled breath of the healthy population. The concentrations on the horizontal axes are shown by logarithmic scales in partsper-billion, ppb. The median values are given in parentheses for each metabolite together with their geometric standard deviation, GSD. Reproduced with permission from RSC from ref. 203.

example malignant human cell cultures and bacterial cultures, will assist and direct the search for in vivo biomarkers of disease or infection via breath analysis. This is an on-going search that has yet to be rewarded to the degree that satisfies practising clinicians, except for important developments in respiratory bacterial infection, as briefly described later. The first SIFT-MS studies investigated volatile compounds emitted by the cancer cell lies CALU-1 and SKMES that revealed the emission of easily measurable amounts of acetaldehyde the release rate correlating well with cell numbers in the cultures. ${ }^{131}$ These results seemed to suggest that this aldehyde might be a biomarker in exhaled breath of lung tumours. However, this hope was soon dispatched by the discovery that some other malignant and non-malignant cells cultured in vitro actually extracted (presumably metabolised) acetaldehyde and higher-order aldehydes from the support culture media. ${ }^{130}$ Nevertheless, acetaldehyde in the headspace of cell cultures, including cells growing in the presence of so-called "scaffolds" of collagen (the three-dimensional, 3D, situation) is proving to be a valuable indicator of the behaviour of cells in a culture. ${ }^{187}$ In this regard, SIFT-MS has also been used to determine the numbers of cells in a culture by quantifying dimethyl sulphide (DMS) in the culture headspace as produced by the cellular enzymatic reduction of dissolved dimethyl sulphoxide (DMSO). ${ }^{215}$

More promising are the SIFT-MS studies of volatile compounds emitted by bacterial cultures. These were initiated at Keele by investigating volatiles emitted by plate cultures of the respiratory bacterium Pseudomonas aeruginosa, PA, which colonises the airways and lungs of those suffering from cystic fibrosis, $C F$. The remarkable discovery was that $P A$ cultures emit gaseous hydrogen cyanide, HCN, at headspace concentrations corresponding to several ppmv, ${ }^{120,121,127,216,217}$ and it turns out that this compound is a genuine biomarker of $P A$ infection in vivo, as is explained below in the next section. This productive work on $P A$ cultures has spawned an extension programme to study volatile compound emissions from other important respiratory bacteria, including $S$. aureus, $S$. pneumoniae and $H$. influenzae, ${ }^{64}$ and S. maltophilia and S.rhizophila strains of the Stenotrophomonas genus, ${ }^{218}$ and the fungal pathogen Aspergillus fumigatus, ${ }^{175}$ the results of which are reported in a recent series of the referenced papers. Copious amounts of volatile compounds are released by these bacterial and fungal species and it is anticipated that some of these compounds may be seen at elevated levels in the exhaled breath of people whose airways are infected with these dangerous pathogens. Exhaled breath studies, which are in train, may reveal if any of these volatile compounds are useful non-invasive biomarkers of respiratory infections.

The "holy grail" in this work would be the recognition of single volatile biomarkers of infection, such as HCN for PA (see below), but this is likely to be a rare occurrence and combinations of compounds are most likely. Then analysis of data using multivariate methods, ${ }^{219}$ such as principal component analysis, can be valuable in distinguishing between the volatile compounds present in the exhaled breath of healthy individuals and those with a specific infections.

\section{Indicators of infection and disease via breath analyses}

The most important and definitive discovery at Keele, which potentially has great value in respiratory medicine, is that gaseous HCN is a true biomarker of $P A$ infection. This has been established by numerous SIFT-MS studies of many genetically-specified strains of $P A$ cultures grown in vitro under planktonic and biofilm conditions. Significantly, it is seen to be elevated in the nose-exhaled breath of patients suffering from $C F$. Differentiating between mouth-exhaled and noseexhaled breath is most important, because HCN is generated in the oral cavity of even healthy persons. ${ }^{220}$ The extensive programme of focused research on this topic was carried out over a decade culminating in a recent extensive multi-centre study involving 8 hospitals in Central England involving $233 \mathrm{CF}$ patients (the "SPACE" study) that has provided essential support for the clinical relevance of $\mathrm{HCN}$ as a biomarker of PA infection in children and young adults. ${ }^{120}$ So HCN in exhaled 
breath can now be exploited as a non-invasive diagnostic for the detection and eradication of the $P A$ bacterium in the airways and lungs, to the advantage and support of CF patients.

Inflammatory bowel disease (IBD) has a relatively large incidence in modern populations and the current diagnostic methods for it are either invasive or have limited sensitivity and specificity. Thus, there is need for new non-invasive methods for its diagnosis and the monitoring of the efficacy of treatment. Recently, interest in real-time quantification of $n$-pentane in exhaled human breath has grown, ${ }^{221}$ since this hydrocarbon is considered to be a valuable biomarker of oxidative stress, lipid peroxidation and inflammation in the body, conditions with which IBD is considered to be associated. Thus, a pilot study of $n$-pentane in the exhaled breath of patient cohorts with Crohn's disease (CD) and ulcerative colitis (UC) and a healthy volunteer cohort has been carried out using a SIFT-MS Profile 3 instrument in a Prague clinic specialising on these diseases. However, before the study could be carried out, a detailed study of the ion chemistry involved in the reaction of the SIFT-MS reagent ion $\mathrm{O}_{2}{ }^{+}$with $n$-pentane had to be carried out to provide the essential kinetics data required to allow accurate analysis of this hydrocarbon in humid breath by SIFT-MS. Pentane was found to be significantly elevated in the breath of both the CD (mean 114 ppbv) and the UC patients (mean $84 \mathrm{ppbv}$ ) relative to the healthy controls (mean 40 ppbv). The detailed results of this clinical study, as well as the ion chemistry study, are given in a recent paper. ${ }^{68}$ Thus, the exciting conclusion is that SIFT-MS can be used to quantify pentane in human breath in real time (single exhalations) avoiding sample collection and storage. This method of analysis may ultimately become a non-invasive screening procedure for inflammatory processes, including IBD. Related to this area, SIFT-MS analyses and multivariate data analysis have been used at the Silsoe Research Institute for the diagnosis of Mycobacterium bovis in wild badgers ${ }^{219}$ based on in vitro studies of production of volatile organic compounds by this bacterium. ${ }^{222}$

\section{The search for volatile biomarkers of oesophageal and gastric cancer}

A group of surgeons and clinicians in the Department of Surgery and Cancer at Imperial College London (leader G.B. Hanna) have a specialist interest in oesophageal and gastric cancer and are involved in a research programme to search for volatile biomarkers of this disease. Their three-pronged attack involves the analysis by SIFT-MS (and partly by GC-MS) of the headspace of gastric content, ${ }^{82,86}$ urine $^{85}$ and exhaled breath, ${ }^{78,81,83,84,223}$ as obtained from patients cohorts with varying stages of these cancers, together with similarly sized cohorts of volunteers free from these diseases. Gastric content is a complex biofluid in the stomach that has an important role in digestive processes. It is believed that gastric content may be a contributory factor in the development of upper gastro-intestinal diseases. Urine is considered an ideal biofluid for clinical investigation, because it is obtained noninvasively and relatively large volumes are easily acquired and it surely carries volatile and non-volatile compounds indicative of physiological status. Exhaled breath analysis of volatile compounds, as has been emphasized in this paper, has great potential in terms of disease diagnosis and measuring physiological response to treatment. These collected studies have revealed that there are some VOCs, including phenol, methyl phenol and hexanoic acid, that discriminate the oesophagogastric cancer cohort from the cancer-free control cohort, the detailed results being given in the cited references above. Single discriminating biomarkers are not identified; rather, the large quantity of SIFT-MS analytical data is treated using the familiar multivariate statistical analyses, as described in the published papers. This group has also pioneered the using of SIFT-MS breath analysis in the operating theatre by carrying out on-line, real time analyses of the exhaled breath of five anaesthetized patients during the complete perioperative periods of laparoscopic surgery. ${ }^{87}$

The above brief reports provide just a flavour of the work carried out in the UK (in association with the Prague group) using SIFT-MS currently at those research centres indicated in Fig. 1. Mention has to be made of the apparently endless search for breath biomarkers of diabetes, and the continuous focus on breath acetone, by a number of groups worldwide, including some in the UK. Studies at the Open University have shown that breath acetone concentration decreases with blood glucose concentration in Type I diabetes mellitus patients during hypoglycaemic clamps. ${ }^{136}$ Off-line breath acetone analysis in critical illness at Nottingham University ${ }^{170}$ has shown that breath concentrations of acetone compare with blood levels of this ketone. But it must be said that there are several confounding factors that disqualify breath acetone as a reliable biomarker of the diabetic state, as identified in a recent paper by the Keele group. ${ }^{135}$ In a similar way, breath ammonia is attractive as an indicator of the uraemic state, but this also must be treated with circumspection because of confounding factors such as oral bacterial generation of ammonia and the well-known fact that the $\mathrm{pH}$ of the saliva and the blood at the alveolar interface strongly influences the partitioning of ammonia between the fluid and gaseous state (exhaled alveolar breath in this case). This and other factors have recently been discussed in a paper concerned with breath analysis in chronic kidney disease and during dialysis, ${ }^{224}$ which also describes the applications of SIFT-MS and FA-MS in renal medicine.

\section{Summary, concluding remarks and a forward look}

The novel analytical techniques SIFT-MS and FA-MS, conceived and developed in the UK, have been described, and a flavour has been given of their uses and applications to ambient trace gas analysis, the focus being on real time breath analysis and the quantification of trace breath biomarkers in healthy volunteers, in disease and infection (SIFT-MS), and the on-line determination of total body water (FA-MS). Other studies relating to physiology and medicine have been carried out at Keele and other UK universities, in Prague and in several other 
laboratories worldwide, ${ }^{74,134,225-228}$ some being summarised in recent review papers. ${ }^{4,21,28}$ An impressive demonstration of the value of on-line, non-invasive analyses by SIFT-MS are the in vitro and in vivo studies of $\mathrm{HCN}$ emitted by the $P A$ bacterium that have established exhaled HCN as a biomarker of $P A$ infection of the lungs and airways of CF patients. ${ }^{120}$ Other similar discoveries are likely as more scientists and enlightened physicians recognise that real time breath analysis is a non-invasive patient-friendly analytical method that can assist clinical diagnosis and therapeutic monitoring.

The strengths, weaknesses, opportunities and threats (SWOT analysis) to SIFT-MS have been presented and discussed in a recent paper. ${ }^{59}$ The main limitations of SIFT-MS relate to (i) the uncertain identification and quantification of analyte ions, and hence of composite trace gas compounds, due to $m / z$ overlaps of analyte ions that can occur when analysing complex mixtures, and (ii) the current limit of quantification, which is currently at the level of ppbv for real-time analyses when many of the trace compounds in exhaled breath and other gaseous matrices are at sub-ppbv levels. The use of high resolution TOF-MS can mitigate these inadequacies and so it is an option to exploit this technology in future SIFT-MS instruments. Further, the operation of instruments must be made simpler such that they can be successfully operated by technicians, scientists and health professionals (such as nurses) without the need for specialist training and knowledge of mass spectrometry and ions chemistry. Notwithstanding these comments, it should be realised that there are few constraints to the application of SIFT-MS in fields where accuracy and precision are not as stringent as in medicine. This is especially so when low molecular mass compounds at relatively high concentrations are to be quantified. However, it remains true that a good understanding of the complex ion chemistry is currently needed by the research worker for the identification and quantification of unknown compounds present at low concentrations; then expert assistance should be sort.

To conclude, we have shown that the versatility of SIFT-MS is such that this UK-developed analytical method has been exploited profitably in many other areas of research and enterprise, as indicated in Table 2. It is confidently expected that SIFT-MS will be exploited to an even greater extent when the instrumentation is made smaller, more analyte specific and sensitive, and of lower cost so that, for example, it can be adopted in general practitioner's surgeries and the clinic (for pre-screening), intensive therapy units (for close non-invasive monitoring) and on-site in factories (for health and safety) and even in supermarkets (for food freshness). Innovative additions to the instrumentation are also under active consideration at Keele and Prague, including the exploitation of switchable drift fields and ion separation by differential mobility in the flow tube reactor in order to improve analyte ion (and hence analyte compound) identification, which are intended to further extend the versatility and utility of this ambient analytical technique.

\section{Acknowledgements}

We would like to thank all our co-workers and colleagues for their contributions to the research discussed in this article, as indicated by their co-authorship of many of the cited papers. We also gratefully acknowledge part funding by GACR, project number 13-28882S, EPSRC, North Staffordshire Medical Institute and Keele University.

\section{References}

1 R. Teranish, A. B. Robinson, P. Cary, T. R. Mon and L. Pauling, Anal. Chem., 1972, 44, 18-20.

2 Volatile biomarkers: Non-Invasive Diagnosis in Physiology and Medicine, ed. A. Amann and D. Smith, Elsevier, 2013.

3 Breath Analysis for Clinical Diagnosis and Therapeutic Monitoring, ed. A. Amann and D. Smith, World Scientific, Singapore, 2005.

4 P. Španěl and D. Smith, Mass Spectrom. Rev., 2011, 30, 236-267.

5 X. Baur, B. Poschadel and L. T. Budnik, Occup. Environ. Med., 2010, 67, 207-212.

6 Evaluation of Biomarkers and Surrogate Endpoints in Chronic Disease, ed. C. M. Micheel and J. R. Ball, The National Academies Press, 2010.

7 T. Ligor, M. Ligor, A. Amann, C. Ager, M. Bachler, A. Dzien and B. Buszewski, J. Breath Res., 2008, 2, 046006.

8 A. Amann, W. Miekisch, J. Pleil, T. Risby and J. Schubert, in Exhaled Biomarkers, ed. I. Horvath and J. C. DeJongste, European Respiratory Society, Sheffield, 2010, pp. 96-114, DOI: 10.1183/1025448x.00018509.

9 D. Smith and P. Španěl, Rapid Commun. Mass Spectrom., 1996, 10, 1183-1198.

10 D. Smith and N. G. Adams, Adv. At. Mol. Phys., 1988, 24, 1-49.

11 D. Smith and P. Španěl, in Linking the gaseous and condensed phases of matter - the behavior of slow electrons, ed. L. G. Christophorou, E. Illenberger and W. F. Schmidt, Plenum Press Div Plenum Publishing Corp, New York, 1994, vol. 326, pp. 487-493.

12 D. Smith, N. G. Adams and E. Alge, J. Phys. B: At., Mol. Opt. Phys., 1984, 17, 461-472.

13 D. Smith, Chem. Rev., 1992, 92, 1473-1485.

14 N. G. Adams and D. Smith, Int. J. Mass Spectrom. Ion Processes, 1976, 21, 349-359.

15 D. Smith and P. Španěl, Int. J. Mass Spectrom, 2015, DOI: 10.1016/j.ijms.2014.05.016, in press.

16 D. Smith and N. G. Adams, Top. Curr. Chem., 1980, 89, 1-43.

17 D. Smith and P. Španěl, Mass Spectrom. Rev., 1995, 14, 255-278.

18 D. Smith and P. Španěl, Acc. Chem. Res., 1992, 25, 414420. 
19 Y. Ikezoe, S. Matsuoka, M. Takebe and A. Viggiano, Gas Phase Ion-Molecule Reaction Rate Constants Through 1986, Maruzen, Tokyo, 1987.

20 V. Anicich, An Index of the Literature for Bimolecular Gas Phase Cation-Molecule Reaction Kinetics, JPL Publication 03-19, National Aeronautics and Space Administration, Jet Propulsion Laboratory, California Institute of Technology, Pasadena, California, 2003.

21 D. Smith and P. Španěl, Mass Spectrom. Rev., 2005, 24, 661-700.

22 P. Španěl and D. Smith, Rapid Commun. Mass Spectrom., 1999, 13, 585-596.

23 P. Španěl and D. Smith, J. Phys. Chem., 1995, 99, 1555115556.

24 D. Smith and P. Španěl, in Atomic, Molecular, and Optical Physics: Charged Particles, Volume 29A (Experimental Methods in the Physical Sciences), eds. F. B. Dunning and R. G. Hulet, Academic Press, New York, 1995, pp. 273-298.

25 D. Smith and P. Španěl, in Encyclopedia of Spectroscopy and Spectrometry, ed. J. Lindon, G. Trantner and J. Holmes, Academic Press, London, 1999, pp. 20922105.

26 D. Smith, A. Pysanenko and P. Španěl, Int. J. Mass Spectrom., 2009, 281, 15-23.

27 K. Giles, N. G. Adams and D. Smith, J. Phys. Chem., 1992, 96, 7645-7650.

28 D. Smith and P. Španěl, Analyst, 2011, 136, 2009-2032.

29 P. Španěl and D. Smith, Curr. Anal. Chem., 2013, 9, 525539.

30 P. Španěl, P. Rolfe, B. Rajan and D. Smith, Ann. Occup. Hyg., 1996, 40, 615-626.

31 D. Smith and P. Španěl, Int. Rev. Phys. Chem., 1996, 15, 231-271.

32 P. Španěl, K. Dryahina and D. Smith, Int. J. Mass Spectrom., 2006, 249, 230-239.

33 K. Dryahina and P. Španěl, Int. J. Mass Spectrom., 2005, 244, 148-154.

34 P. Španěl and D. Smith, J. Am. Soc. Mass Spectrom., 2001, 12, 863-872.

35 P. Španěl and D. Smith, Int. J. Mass Spectrom., 1997, 167, 375-388.

36 P. Španěl, T. S. Wang and D. Smith, Int. J. Mass Spectrom., 2002, 218, 227-236.

37 D. Smith, T. S. Wang and P. Španěl, Rapid Commun. Mass Spectrom., 2003, 17, 2655-2660.

38 P. Španěl, Y. F. Ji and D. Smith, Int. J. Mass Spectrom., 1997, 165, 25-37.

39 P. Španěl, J. M. Van Doren and D. Smith, Int. J. Mass Spectrom., 2002, 213, 163-176.

40 P. Španěl and D. Smith, Int. J. Mass Spectrom., 1998, 172, 137-147.

41 P. Španěl and D. Smith, Int. J. Mass Spectrom., 1998, 172, 239-247.

42 P. Španěl and D. Smith, Int. J. Mass Spectrom., 1998, 176, 167-176.
43 P. Španěl and D. Smith, Int. J. Mass Spectrom., 1999, 187, 139-147.

44 P. Španěl and D. Smith, Int. J. Mass Spectrom., 1998, 176, 203-211.

45 A. M. Diskin, T. S. Wang, D. Smith and P. Španěl, Int. J. Mass Spectrom., 2002, 218, 87-101.

46 P. Španěl and D. Smith, Int. J. Mass Spectrom., 1998, 181, 1-10.

47 T. S. Wang, P. Španěl and D. Smith, Int. J. Mass Spectrom., 2003, 228, 117-126.

48 N. Schoon, C. Amelynck, L. Vereecken and E. Arijs, Int. J. Mass Spectrom., 2003, 229, 231-240.

49 P. Španěl and D. Smith, Int. J. Mass Spectrom., 1999, 184, 175-181.

50 P. Španěl and D. Smith, Int. J. Mass Spectrom., 1999, 189, 213-223.

51 T. S. Wang, P. Španěl and D. Smith, Int. J. Mass Spectrom., 2004, 239, 139-146.

52 P. Španěl and D. Smith, Rapid Commun. Mass Spectrom., 2000, 14, 1136-1140.

53 P. Španěl, T. S. Wang and D. Smith, Rapid Commun. Mass Spectrom., 2004, 18, 1869-1873.

54 P. Španěl, S. Davies and D. Smith, Rapid Commun. Mass Spectrom., 1998, 12, 763-766.

55 D. A. Fairley, D. B. Milligan, C. G. Freeman, M. J. McEwan, P. Španěl and D. Smith, Int. J. Mass Spectrom., 1999, 193, 35-43.

56 K. Sovová, K. Dryahina and P. Španěl, Int. J. Mass Spectrom., 2011, 300, 31-38.

57 D. Smith and N. G. Adams, J. Chem. Soc., Faraday Trans., 1989, 85, 1613-1630.

58 P. Španěl and D. Smith, Rapid Commun. Mass Spectrom., 2000, 14, 1898-1906.

59 D. Smith and P. Španěl, Eur. J. Mass Spectrom., 2013, 19, 225-246.

60 R. B. Michalčíková and P. Španěl, Int. J. Mass Spectrom., 2014, 368, 15-22.

61 A. Pysanenko, P. Španěl and D. Smith, J. Breath Res., 2008, 2, 046004 .

62 D. Smith, T. S. Wang, A. Pysanenko and P. Španěl, Rapid Commun. Mass Spectrom., 2008, 22, 783-789.

63 T. S. Wang, A. Pysanenko, K. Dryahina, P. Španěl and D. Smith, J. Breath Res., 2008, 2, 037013.

64 T. W. E. Chippendale, F. J. Gilchrist, P. Španěl, A. Alcock, W. Lenney and D. Smith, Anal. Methods, 2014, 6, 24602472.

65 P. Španěl and D. Smith, Curr. Anal. Chem., 2013, 9, 523524.

66 F. J. Gilchrist, R. J. Bright-Thomas, A. M. Jones, D. Smith, P. Španěl, A. K. Webb and W. Lenney, J. Breath Res., 2013, $7,7$.

67 P. Španěl, K. Dryahina and D. Smith, J. Breath Res., 2013, 7, 017106.

68 K. Dryahina, P. Španěl, V. Pospisilova, K. Sovova, L. Hrdlicka, N. Machkova, M. Lukas and D. Smith, Rapid Commun. Mass Spectrom., 2013, 27, 1983-1992. 
69 P. Španěl, K. Dryahina, A. Rejskova, T. W. E. Chippendale and D. Smith, Physiol. Meas., 2011, 32, N23-N31.

70 V. Shestivska, A. Nemec, P. Drevinek, K. Sovová, K. Dryahina and P. Španěl, Rapid Commun. Mass Spectrom., 2011, 25, 2459-2467.

71 V. Pazdera, M. Fousek, M. Ferus, K. Dryahina, P. Španěl, V. Shestivska and S. Civiš, Czech J. Phys., 2011, 61, 67.

72 K. Dryahina, D. Smith and P. Španěl, Rapid Commun. Mass Spectrom., 2010, 24, 1296-1304.

73 K. Dryahina, F. Pehal, D. Smith and P. Španěl, Int. J. Mass Spectrom., 2009, 286, 1-6.

74 A. Hryniuk and B. M. Ross, J. Gastrointest. Liver Dis., 2010, 19, 15-20.

75 B. M. Ross, BMC Res Notes, 2008, 1, 41.

76 B. M. Ross, S. Babay and C. Ladouceur, Rapid Commun. Mass Spectrom., 2009, 23, 3973-3982.

77 B. M. Ross and N. Vermeulen, Rapid Commun. Mass Spectrom., 2007, 21, 3608-3612.

78 J. Huang, S. Kumar and G. B. Hanna, J. Breath Res., 2014, 8, 037104.

79 S. Kumar, J. Huang, N. Abbassi-Ghadi, H. Mackenzie, J. Hoare, P. Spanel, D. Smith and G. B. Hanna, Br. J. Surg., 2014, 101, 17-18.

80 J. Z. Huang, S. Kumar and G. B. Hanna, J. Breath Res., 2014, 8, 037104.

81 S. Kumar, J. Z. Huang, N. Abbassi-Ghadi, P. Španěl, D. Smith and G. B. Hanna, Anal. Chem., 2013, 85, 61216128.

82 S. Kumar, J. Huang and G. B. Hanna, Br. J. Surg., 2013, 100, 4-4.

83 J. Z. Huang, S. Kumar, A. Singanayagam, P. M. George, O. M. Kon, M. Takata and G. B. Hanna, Anal. Methods, 2013, 5, 3807-3810.

84 J. Z. Huang, S. Kumar, P. R. Boshier, S. Wakefield, J. R. Cushnir and G. B. Hanna, Curr. Anal. Chem., 2013, 9, 584-592.

85 J. Z. Huang, S. Kumar, N. Abbassi-Ghadi, P. Španěl, D. Smith and G. B. Hanna, Anal. Chem., 2013, 85, 34093416.

86 S. Kumar, J. Z. Huang, J. R. Cushnir, P. Španěl, D. Smith and G. B. Hanna, Anal. Chem., 2012, 84, 9550-9557.

87 P. R. Boshier, J. R. Cushnir, V. Mistry, A. Knaggs, P. Španěl, D. Smith and G. B. Hanna, Analyst, 2011, 136, 3233-3237.

88 P. R. Boshier, N. Marczin and G. B. Hanna, J. Am. Soc. Mass Spectrom., 2010, 21, 1070-1074.

89 P. R. Boshier, J. R. Cushnir, O. H. Priest, N. Marczin and G. B. Hanna, J. Breath Res., 2010, 4, 031001.

90 P. Boshier, O. Priest, G. Hanna and N. Marczin, Am. J. Respir. Crit. Care Med., 2009, 179, 1.

91 S. Saad, K. Hewett and J. Greenman, J. Breath Res., 2012, 6, 016001.

92 R. M. S. Thorn, D. M. Reynolds and J. Greenman, J. Microbiol. Methods, 2011, 84, 258-264.

93 P. Španěl and D. Smith, Med. Biol. Eng. Comput., 1996, 34, 409-419.
94 J. Glosik, A. B. Rakshit, N. D. Twiddy, N. G. Adams and D. Smith, J. Phys. B: At., Mol. Opt. Phys., 1978, 11, 33653379.

95 M. Tichy, A. B. Rakshit, D. G. Lister, N. D. Twiddy, N. G. Adams and D. Smith, Int. J. Mass Spectrom. Ion Processes, 1979, 29, 231-247.

96 O. A. Ajibola, D. Smith, P. Španěl and G. A. A. Ferns, J. Nutr. Sci., 2013, e34, DOI: 10.1017/jns.2013.26.

97 P. Španěl, S. Davies and D. Smith, FASEB J., 2000, 14, A490-A490.

98 D. Smith, P. Španěl and S. Davies, J. Appl. Physiol., 1999, 87, 1584-1588.

99 D. Smith, A. Pysanenko and P. Španěl, Rapid Commun. Mass Spectrom., 2010, 24, 1066-1074.

100 P. Španěl, T. S. Wang and D. Smith, Physiol. Meas., 2005, 26, 447-457.

101 D. Smith, T. S. Wang and P. Španěl, Physiol. Meas., 2002, 23, 477-489.

102 P. Španěl, C. Turner, T. S. Wang, R. Bloor and D. Smith, Physiol. Meas., 2006, 27, N7-N17.

103 D. Smith, T. W. E. Chippendale, K. Dryahina and P. Španěl, Curr. Anal. Chem., 2013, 9, 565-575.

104 S. T. Senthilmohan, D. B. Milligan, M. J. McEwan, C. G. Freeman and P. F. Wilson, Redox Rep., 2000, 5, 151153.

105 A. Pysanenko, T. Wang, P. Španěl and D. Smith, Rapid Commun. Mass Spectrom., 2009, 23, 1097-1104.

106 T. Wang, P. Španěl and D. Smith, Int. J. Mass Spectrom., 2008, 272, 78-85.

107 D. Smith, K. M. K. Ismail, A. M. Diskin, G. Chapman, J. L. Magnay, P. Španěl and S. O'Brien, Acta Obstet. Gynecol. Scand., 2006, 85, 1008-1011.

108 A. M. Diskin, P. Španěl and D. Smith, Physiol. Meas., 2003, 24, 191-199.

109 C. Turner, B. Parekh, C. Walton, P. Španěl, D. Smith and M. Evans, Rapid Commun. Mass Spectrom., 2008, 22, 526532.

110 R. N. Bloor, P. Španěl and D. Smith, Addict. Biol., 2006, 11, 163-169.

111 I. Kushch, K. Schwarz, L. Schwentner, B. Baumann, A. Dzien, A. Schmid, K. Unterkofler, D. Gastl, P. Španěl, D. Smith and A. Amann, J. Breath Res., 2008, 026002, DOI: 10.1088/1752-7155/2/2/026002.

112 R. N. Bloor, T. S. Wang, P. Španěl and D. Smith, Addiction, 2008, 103, 1671-1677.

113 S. J. Davies, P. Španěl and D. Smith, Nephrol., Dial., Transplant., 2001, 16, 836-839.

114 P. Španěl, S. Davies and D. Smith, Rapid Commun. Mass Spectrom., 1999, 13, 1733-1738.

115 S. Davies, P. Španěl and D. Smith, Kidney Int., 1997, 52, 223-228.

116 B. John, B. K. Tan, S. Dainty, P. Španěl, D. Smith and S. J. Davies, Clin. J. Am. Soc. Nephrol., 2010, 5, 14631470 .

117 C. Chan, C. McIntyre, D. Smith, P. Španěl and S. J. Davies, Clin. J. Am. Soc. Nephrol., 2009, 4, 1791-1798. 
118 C. Chan, D. Smith, P. Španěl, C. W. McIntyre and S. J. Davies, Nephrol., Dial., Transplant., 2008, 23, 20642070.

119 S. J. Davies, P. Španěl and D. Smith, Physiol. Meas., 2001, 22, 651-659.

120 D. Smith, P. Španěl, F. J. Gilchrist and W. Lenney, J. Breath Res., 2013, 7, 044001.

121 F. J. Gilchrist, H. Sims, A. Alcock, J. Belcher, A. M. Jones, D. Smith, P. Španěl, A. K. Webb and W. Lenney, Anal. Methods, 2012, 4, 3661-3665.

122 F. J. Gilchrist, C. Razavi, A. K. Webb, A. M. Jones, P. Španěl, D. Smith and W. Lenney, J. Breath Res., 2012, 6, 036004.

123 B. Enderby, D. Smith, W. Carroll and W. Lenney, Pediatr. Pulmonol., 2009, 44, 142-147.

124 F. J. Gilchrist, R. J. Bright-Thomas, A. M. Jones, D. Smith, P. Španěl, A. K. Webb and W. Lenney, J. Breath Res., 2013, 7, 026010.

125 J. Julak, E. Stranska, V. Rosova, H. Geppert, P. Španěl and D. Smith, J. Microbiol. Methods, 2006, 65, 76-86.

126 V. Shestivska, P. Španěl, K. Dryahina, K. Sovová, D. Smith, M. Musilek and A. Nemec, J. Appl. Microbiol., 2012, 113, 701-713.

127 W. Carroll, W. Lenney, T. S. Wang, P. Španěl, A. Alcock and D. Smith, Pediatr. Pulmonol., 2005, 39, 452-456.

128 D. Smith, P. Španěl and J. Sule-Suso, Expert Rev.Mol. Diagn., 2010, 10, 255-257.

129 P. Španěl and D. Smith, J. Breath Res., 2008, 2, 046003.

130 J. Sule-Suso, A. Pysanenko, P. Španěl and D. Smith, Analyst, 2009, 134, 2419-2425.

131 D. Smith, T. S. Wang, J. Sule-Suso, P. Španěl and A. El Haj, Rapid Commun. Mass Spectrom., 2003, 17, 845-850.

132 P. Španěl, D. Smith, T. A. Holland, W. Al Singary and J. B. Elder, Rapid Commun. Mass Spectrom., 1999, 13, 1354-1359.

133 D. Smith, P. Španěl, T. A. Holland, W. Al Singari and J. B. Elder, Rapid Commun. Mass Spectrom., 1999, 13, 724729.

134 M. Storer, J. Dummer, H. Lunt, J. Scotter, F. McCartin, J. Cook, M. Swanney, D. Kendall, F. Logan and M. Epton, J. Breath Res., 2011, 5, 046011.

135 D. Smith, P. Španěl, A. A. Fryer, F. Hanna and G. A. A. Ferns, J. Breath Res., 2011, 5, 022001.

136 C. Turner, C. Walton, S. Hoashi and M. Evans, J. Breath Res., 2009, 3, 046004.

137 A. Olivares, K. Dryahina, J. L. Navarro, M. Flores, D. Smith and P. Španěl, Anal. Chem., 2010, 82, 5819-5829.

138 B. M. Davis and M. J. McEwan, J. Agric. Food Chem., 2007, 55, 3334-3338.

139 B. M. Davis, S. T. Senthilmohan, P. F. Wilson and M. J. McEwan, Rapid Commun. Mass Spectrom., 2005, 19, 2272-2278.

140 N. Sumonsiri and S. A. Barringer, Curr. Anal. Chem., 2013, 9, 631-641.

141 A. Agila and S. Barringer, J. Food Sci., 2013, 78, C184C191.
142 B. Wampler and S. A. Barringer, J. Food Sci., 2012, 77, C677-C683.

143 P. Ties and S. Barringer, J. Food Sci., 2012, 77, C830-C837.

144 R. Mosneaguta, V. Alvarez and S. A. Barringer, J. Food Sci., 2012, 77, C1234-C1240.

145 V. S. Langford, C. J. Reed, D. B. Milligan, M. J. McEwan, S. A. Barringer and W. J. Harper, J. Food Sci., 2012, 77, C719-C726.

146 T. Bowman and S. Barringer, J. Food Sci., 2012, 77, C51C60.

147 A. Agila and S. Barringer, J. Food Sci., 2012, 77, C461C468.

148 A. Agila and S. Barringer, J. Food Sci., 2012, 77, C1103C1108.

149 G. Ozcan and S. Barringer, J. Food Sci., 2011, 76, C324C333.

150 Y. Huang and S. A. Barringer, J. Food Sci., 2011, 76, C279C286.

151 X. S. Huang, H. Y. Duan and S. A. Barringer, LWT-Food Sci. Technol., 2011, 44, 1761-1765.

152 Y. C. Xu and S. Barringer, J. Food Sci., 2010, 75, C352C358.

153 Y. C. Xu and S. Barringer, J. Agric. Food Chem., 2009, 57, 9108-9113.

154 P. Španěl, J. Cocker, B. Rajan and D. Smith, Ann. Occup. Hyg., 1997, 41, 373-382.

155 D. Smith, P. Španěl, D. Dabill, J. Cocker and B. Rajan, Rapid Commun. Mass Spectrom., 2004, 18, 2830-2838.

156 D. Smith, P. Cheng and P. Španěl, Rapid Commun. Mass Spectrom., 2002, 16, 1124-1134.

157 D. Hastie, J. Gray, V. Langford, R. Maclagan, D. Milligan and M. McEwan, Rapid Commun. Mass Spectrom., 2010, 24, 343-348.

158 V. S. Langford, J. D. C. Gray and M. J. McEwan, Rapid Commun. Mass Spectrom., 2013, 27, 700-706.

159 B. J. Prince, D. B. Milligan and M. J. McEwan, Rapid Commun. Mass Spectrom., 2010, 24, 1763-1769.

160 G. J. Francis, V. S. Langford, D. B. Milligan and M. J. McEwan, Anal. Chem., 2009, 81, 1595-1599.

161 K. Sovová, M. Ferus, I. Matulkova, P. Španěl, K. Dryahina, O. Dvorak and S. Civiš, Mol. Phys., 2008, 106, 12051214.

162 D. Smith, P. Španěl and J. B. Jones, Bioresour. Technol., 2000, 75, 27-33.

163 C. Hurst, P. Longhurst, S. Pollard, R. Smith, B. Jefferson and J. Gronow, Environ. Pollut., 2005, 135, 171-177.

164 X. Baur, F. Yu, B. Poschadel, W. Veldman and T. Knol-de Vos, Int. Marit. Health, 2006, 57, 46-55.

165 M. Civiš, S. Civiš, K. Sovová, K. Dryahina, P. Španěl and M. Kyncl, Anal. Chem., 2011, 83, 1069-1077.

166 K. Sovová, K. Dryahina, P. Španěl, M. Kyncl and S. Civiš, Analyst, 2010, 1106-1114, DOI: 10.1039/b926425f.

167 P. F. Wilson, B. J. Prince and M. J. McEwan, Anal. Chem., 2006, 78, 575-579.

168 D. B. Milligan, G. J. Francis, B. J. Prince and M. J. McEwan, Anal. Chem., 2007, 79, 2537-2540. 
169 S. C. Sturney, M. K. Storer, G. M. Shaw, D. E. Shaw and M. J. Epton, J. Breath Res., 2013, 7, 9.

170 S. C. Sturney, M. K. Storer, G. M. Shaw, R. R. Kennedy, D. E. Shaw and M. J. Epton, Thorax, 2013, 68, A158A158.

171 M. Storer, J. Dummer, S. Sturney and M. Epton, Curr. Anal. Chem., 2013, 9, 576-583.

172 J. Dummer, M. Storer, S. Sturney, A. Scott-Thomas, S. Chambers, M. Swanney and M. Epton, J. Breath Res., 2013, 7, 017105.

173 G. J. Francis, D. B. Milligan and M. J. McEwan, Anal. Chem., 2009, 81, 8892-8899.

174 V. Langford, J. Gray, B. Foulkes, P. Bray and M. J. McEwan, J. Agric. Food Chem., 2012, 60, 6806-6815.

175 T. W. E. Chippendale, F. J. Gilchrist, P. Spanel, A. Alcock, W. Lenney and D. Smith, Anal. Methods, 2014, 6, 81548164.

176 D. Smith, T. W. E. Chippendale and P. Španěl, Rapid Commun. Mass Spectrom., 2014, 28, 1917-1928.

177 D. Smith, K. Sovová and P. Španěl, Int. J. Mass Spectrom., 2012, 319, 25-30.

178 D. Smith, T. W. E. Chippendale and P. Španěl, Int. J. Mass Spectrom., 2011, 303, 81-89.

179 T. S. Wang, P. Španěl and D. Smith, Int. J. Mass Spectrom., 2004, 237, 167-174.

180 T. S. Wang, D. Smith and P. Španěl, Int. J. Mass Spectrom., 2004, 233, 245-251.

181 P. Španěl, A. M. Diskin, T. Wang and D. Smith, Int. J. Mass Spectrom., 2003, 228, 269-283.

182 D. Smith, T. S. Wang and P. Španěl, Int. J. Mass Spectrom., 2003, 230, 1-9.

183 T. S. Wang, D. Smith and P. Španěl, Rapid Commun. Mass Spectrom., 2002, 16, 1860-1870.

184 P. Španěl and D. Smith, Rapid Commun. Mass Spectrom., 2000, 14, 646-651.

185 P. Španěl and D. Smith, Rapid Commun. Mass Spectrom., 2001, 15, 563-569.

186 D. Smith, A. Pysanenko and P. Španěl, Rapid Commun. Mass Spectrom., 2009, 23, 1419-1425.

187 A. V. Rutter, T. W. E. Chippendale, Y. Yang, P. Španěl, D. Smith and J. Sule-Suso, Analyst, 2013, 138, 91-95.

188 K. Sovova, J. Cepl, A. Markos and P. Španěl, Analyst, 2013, 138, 4795-4801.

189 T. W. E. Chippendale, P. Španěl and D. Smith, Rapid Commun. Mass Spectrom., 2011, 25, 2163-2172.

190 P. Španěl and D. Smith, Rapid Commun. Mass Spectrom., 2001, 15, 867-872.

191 D. Smith and P. Španěl, Rapid Commun. Mass Spectrom., 2001, 15, 25-32.

192 W. W. Wong, W. J. Cochran, W. J. Klish, E. O. Smith, L. S. Lee and P. D. Klein, Am. J. Clin. Nutr., 1987, 45, 834834.

193 P. Španěl and D. Smith, J. Am. Soc. Mass Spectrom., 2000, 11, 866-875.

194 P. Španěl, V. Shestivska, T. W. E. Chippendale and D. Smith, J. Am. Soc. Mass Spectrom., 2011, 22, 179-186.
195 D. Smith, B. Engel, P. Španěl, A. Diskin and S. Davies, Int. J. Body Compos. Res., 2004, 2, 99-106.

196 D. Smith, B. Engel, A. M. Diskin, P. Španěl and S. J. Davies, Am. J. Clin. Nutr., 2002, 76, 1295-1301.

197 S. J. Davies, B. Engel, C. Chan, B. K. Tan, Z. Yu, R. Asghar, B. John, P. Spanel and D. Smith, Curr. Anal. Chem., 2013, 9, 593-599.

198 C. Turner, P. Španěl and D. Smith, Physiol. Meas., 2006, 27, 321-337.

199 C. Turner, P. Španěl and D. Smith, Physiol. Meas., 2006, $27,13-22$

200 C. Turner, P. Španěl and D. Smith, Rapid Commun. Mass Spectrom., 2006, 20, 61-68.

201 C. Turner, P. Španěl and D. Smith, Physiol. Meas., 2006, 27, 637-648.

202 D. Smith, C. Turner and P. Španěl, J. Breath Res., 2007, 1, 014004.

203 D. Smith and P. Španěl, Analyst, 2007, 132, 390-396.

204 A. M. Diskin, P. Španěl and D. Smith, Physiol. Meas., 2003, 24, 107-119.

205 C. Walton, M. Patel, D. Pitts, P. Knight, S. Hoashi, M. Evans and C. Turner, J Breath Res, 2014, 8, 037108.

206 C. Lourenco and C. Turner, Metabolites, 2014, 4, 465498.

207 M. A. Turner, S. Bandelow, L. Edwards, P. Patel, H. J. Martin, I. D. Wilson and C. L. Thomas, J Breath Res, 2013, 7, 017102.

208 C. Guallar-Hoyas, M. A. Turner, G. J. Blackburn, I. D. Wilson and C. L. Thomas, Bioanalysis, 2012, 4, 22272237.

209 M. A. Turner, C. Guallar-Hoyas, A. L. Kent, I. D. Wilson and C. L. Thomas, Bioanalysis, 2011, 3, 2731-2738.

210 C. Turner, H. Knobloch, J. Richards, P. Richards, T. T. F. Mottram, D. Marlin and M. A. Chambers, Biosyst. Eng., 2012, 112, 75-81.

211 C. Turner, C. Batty, E. Escalona, J. O. Hunter and C. Proudman, Curr. Anal. Chem., 2013, 9, 614-621.

212 C. Turner, B. Parekh, C. Walton, P. Spanel, D. Smith and M. Evans, Rapid Commun. Mass Spectrom., 2008, 22, 526532.

213 C. Turner, Expert Rev. Mol. Diagn., 2011, 11, 497-503.

214 J. Dummer, M. Storer, M. Swanney, M. McEwan, A. ScottThomas, S. Bhandari, S. Chambers, R. Dweik and M. Epton, TRaC, Trends Anal. Chem., 2011, 30, 960-967.

215 T. W. Chippendale, P. Spanel, D. Smith and A. J. El Haj, Analyst, 2014, 139, 4903-4907.

216 W. Lenney and F. J. Gilchrist, Eur. Respir. J., 2011, 37, 482483.

217 F. J. Gilchrist, A. Alcock, J. Belcher, M. Brady, A. Jones, D. Smith, P. Španěl, K. Webb and W. Lenney, Eur. Respir. J., 2011, 38, 409-414.

218 V. Shestivska, K. Dryahina, J. Nunvár̆, K. Sovová, D. Elhottová, D. Smith and P. Španěl, J. Breath Res., 2015, In press.

219 A. D. Spooner, C. Bessant, C. Turner, H. Knobloch and M. Chambers, Analyst, 2009, 134, 1922-1927. 
220 P. Španěl, K. Dryahina and D. Smith, J. Breath Res., 2007, 1, 011001.

221 B. Ross, S. Shah and M. Peet, Open Journal of Psychiatry, 2011, 1, 1-7.

222 R. McNerney, K. Mallard, P. I. Okolo and C. Turner, FEMS Microbiol. Lett., 2012, 328, 150-156.

223 P. R. Boshier, V. Mistry, J. R. Cushnir, O. M. Kon, S. L. Elkin, S. Curtis, N. Marczin and G. B. Hanna, J. Surg. Res., 2015, 193, 704-712.

224 S. J. Davies, P. Španěl and D. Smith, Bioanalysis, 2014, 6, 843-857.

225 I. R. White, K. A. Willis, C. Whyte, R. Cordell, R. S. Blake, A. J. Wardlaw, S. Rao, J. Grigg, A. M. Ellis and P. S. Monks, J. Breath Res., 2013, 7, 017112.
226 K. Van Huffel, P. M. Heynderickx, J. Dewulf and H. Van Langenhove, in Nose 2012: 3rd International Conference on Environmental Odour Monitoring and Control, ed. R. DelRosso, S. Pierucci and J. J. Klemes, 2012, vol. 30, pp. 67-72.

227 P. M. Heynderickx, K. Van Huffel, J. Dewulf and H. Van Langenhove, in Nose 2012: 3rd International Conference on Environmental Odour Monitoring and Control, ed. R. DelRosso, S. Pierucci and J. J. Klemes, 2012, vol. 30, pp. 157-162.

228 M. A. Samara, W. H. W. Tang, F. Cikach, Z. Gul, L. Tranchito, K. M. Paschke, J. Viterna, Y. P. Wu, D. Laskowski and R. A. Dweik, J. Am. Coll. Cardiol., 2013, 61, 1463-1464. 